\title{
Silencing long noncoding RNA LINC01138 inhibits aerobic glycolysis to reduce glioma cell proliferation by regulating the microRNA-375/SP1 axis
}

\author{
CHENGNING XU, HAORAN YIN, XI JIANG and CHUNMING SUN \\ Department of Neurosurgery, The First Affiliated Hospital of Soochow University, Suzhou, Jiangsu 215006, P.R. China
}

Received February 22, 2021; Accepted August 10, 2021

DOI: $10.3892 / \mathrm{mmr} .2021 .12486$

\begin{abstract}
Glioma is a primary cerebral neoplasm that originates from glial tissue and spreads to the central nervous system. Long noncoding RNAs are known to play a role in glioma cells by regulating cell proliferation, migration and invasion. The aim of the present study was to investigate the mechanism by which long intergenic non-protein coding RNA (LINC) 01138 affects glycolysis and proliferation in glioma cells via the microRNA (miR)-375/specificity protein 1 (SP1) axis. LINC01138 expression was assessed in glioma tissues and cells using reverse transcription-quantitative PCR and the association between LINC01138 and patient clinicopathological features was analyzed. Glucose uptake, lactic acid secretion, cell proliferation, and glycolysis-related enzyme levels were detected following LINC01138 silencing using CCK-8, EDU assay and western blot analysis. miR-375 and SP1 expression levels were also assessed, and the distribution of LINC01138 in the nucleus and cytoplasm was investigated using subcellular fractionation localization. Furthermore, the binding relationships between LINC01138 and miR-375, and between miR-375 and SP1 were assessed via dual-luciferase experiment, RIP and RNA pull-down assays. Finally, xenograft transplantation models were used to verify the in vitro results. LINC01138 was highly expressed in glioma, which was independent of patient sex or age but was significantly related to tumor diameter, the World Health Organization tumor grade and lymph node metastasis. Silencing LINC01138 significantly reduced glioma glycolysis and cell proliferation. Moreover, LINC01138 acted as a competing endogenous RNA to sponge miR-375 and promote SP1 expression. miR-375 inhibition significantly reversed the effect of LINC01138
\end{abstract}

Correspondence to: Professor Chunming Sun, Department of Neurosurgery, The First Affiliated Hospital of Soochow University, 899 Pinghai Road, Gusu, Suzhou, Jiangsu 215006, P.R. China

E-mail: drsunchunming001@163.com

Key words: long noncoding RNA, long intergenic non-protein coding RNA 01138, microRNA-375, specificity protein 1, human glioma, proliferation, glycolysis, competing endogenous RNA, subcellular localization silencing. In addition, silencing LINC01138 significantly reduced tumor growth in vivo. The present study demonstrated that silencing LINC01138 inhibited aerobic glycolysis and thus reduced glioma cell proliferation, potentially by modulating the miR-375/SP1 axis.

\section{Introduction}

Glioma is a primary cerebral neoplasm that originates from glial tissue and spreads to the central nervous system. Glioma accounts for $31 \%$ of the central nervous system tumors in adults and is characterized by diverse histopathological changes, poor clinical outcomes and high aggressiveness $(1,2)$. The clinical heterogeneity, rapid cell dissemination, invasion and frequent recurrence of glioma results in high incidence and mortality rates, with the 5-year survival rate of patients with glioma being $2 \%(3,4)$. Studies show that every year, $\sim 100,000$ people worldwide are diagnosed as having diffuse glioma (5), and the proportion of patient death within 1 month and 3 months after the diagnosis was 9.24 and $19.15 \%$ respectively for all glioma patients (6). Moreover, patients with glioma often suffer from complications, including epilepsy, extensive neurodegeneration and cognitive impairment, due to aberrant glutamate secretion in the glioma microenvironment (7). Glioma grading is beneficial for the prevention, control and prognosis of glioma (8). Multiple chemical and biomedical management strategies, including ultrasound, receptor-targeted methods, and local therapeutic delivery by interstitial spray and polymeric hydrogels, are all beneficial for patients with glioma (9). Despite these available treatments, the prognosis and survival rate of patients with glioma remain poor, and the development of new effective treatments for glioma is challenging (10). Therefore, the identification of novel therapeutic targets for glioma is desperately needed.

Aerobic glycolysis, the metabolism of glucose to lactate, is commonly enhanced in cancer and is a malignant adaptation that allows for continued cell proliferation in diverse brain tumor microenvironments (11). Lactic acid, the final product of the glycolysis pathway, can only accumulate in cells or be transported out of cells by specific transporters. Intracellular lactic acid content can therefore act as one of the principal biochemical markers of the intracellular glycolysis rate (12). Glucose transporter (GLUT) is required for the transport of glucose into cells and hexokinase (HK) is required for glucose 
phosphorylation. Next, the phosphorylated glucose is isomerized into fructose, whereas phosphofructokinase (PFK) is responsible for the phosphorylation of fructose. Following a series of reactions, pyruvate kinase (PK) catalyzes ADP to generate ATP (13-15). Compared with healthy cells, the altered metabolism of cancer cells means they depend heavily on aerobic glycolysis for proliferation. Interference with tumor-specific glycolysis-related enzymes is a potential and promising method for the treatment of glioma (16). The present study therefore aimed to explore the mechanism of aerobic glycolysis in human glioma cell proliferation.

Long noncoding RNAs (lncRNAs) have been identified as promising biomarkers that serve as oncogenes or tumor suppressors, with lncRNA dysregulation being a necessary step in tumor growth and metastasis (17). Furthermore, lncRNAs are involved in the progression of a wide range of glioma neoplasms, regulating cell cycle progression, mediating apoptotic pathways and changing cancer cell behavior (18). Long intergenic non-protein coding RNA (LINC) 01138 is a known oncogene, and is highly expressed in hepatocellular cancer, prostate cancer and clear cell renal cell carcinoma (ccRCC). LINC01138 expression is also closely correlated with poor overall survival rates (19). However, the expression patterns and function of LINC01138 during glioma progression remain largely unknown. Therefore, the present study attempted to determine the role and underlying mechanisms of LINC01138 in glioma.

Salmena et al (20) demonstrated that lncRNAs may act as competing endogenous RNAs (ceRNAs), interacting with microRNAs (miRs) in human cancer. A recent study reported that LINC01138 may facilitate gastric cancer progression by sponging miR-1273e (21). However, to the best of our knowledge, the ceRNA network of LINC01138 has not been reported. Furthermore, miRs have been demonstrated to be promotors or inhibitors of different types of cancer, including glioma (22). Evidence has shown that miR-375 expression is often downregulated in various types of cancer (23-25). Notably, the ceRNA interaction between miR-375 and lncRNAs could modulate the pathogenesis and development of colon adenocarcinoma and triple-negative breast cancer $(26,27)$. Several studies have demonstrated that the lncRNA/miR/mRNA axis serves a role in colorectal cancer, ovarian cancer and thyroid carcinoma and thus affects cancer progression (28-30). Furthermore, specificity protein 1 (SP1) upregulation has been reported to enhance glioma self-renewal and to predict a poor prognosis (31). As a downstream gene in the lncRNA/miR/mRNA axis, SP1 has been determined to be regulated by lncRNA-miR crosstalk in various types of cancer, including non-small cell lung cancer and lung adenocarcinoma $(32,33)$. SP1 is involved in the occurrence and malignancy of multiple neoplasms; however, how it functions in glioma remains unclear (34). It was therefore hypothesized that there may be crosstalk between LINC01138, miR-375 and SP1 in glioma. The present study aimed to explore the effect of LINC01138, miR-375 and SP1 in glioma.

\section{Materials and methods}

Ethical standards. The present study was approved and supervised by the Ethics Committee of The First Affiliated
Hospital of Soochow University (Suzhou, China; approval no. SDU-MED-2017-085), and was in accordance with the Declaration of Helsinki. Animal experiments were approved by the Animal Ethics Committee of The First Affiliated Hospital of Soochow University (approval no. S20200616018) and followed the guidelines of Animal Research: Reporting of In Vivo Experiments 2.0 (35).

Tissue sample collection. Between January 2018 and January 2019, 108 pairs (54 males and 54 females) of glioma tissues and adjacent normal brain tissues were collected at The First Affiliated Hospital of Soochow University. According to the World Health Organization (WHO) tumor grade criteria (36), 62 tissue samples were grade I + II tumors, and 46 tissue samples were grade III + IV tumors. No patient received any treatment prior to sample collection. The extracted tissues were immediately frozen and stored in liquid nitrogen.

Cell culture. Immortalized normal human astrocytes (NHAs) HASTR/ci35, human glioma cell lines (A172, U251MG, TJ899 and TJ905 cells) and 293T cells (all purchased from The Cell Bank of Type Culture Collection of The Chinese Academy of Sciences), were cultured in Dulbecco's modified Eagle's medium (DMEM; Gibco; Thermo Fisher Scientific, Inc.) containing $10 \%$ fetal bovine serum (FBS; Thermo Fisher Scientific, Inc.) and penicillin $(100 \mu \mathrm{g} / \mathrm{ml})$-streptomycin $(100 \mathrm{U} / \mathrm{ml})$ at $37^{\circ} \mathrm{C}$ in $5 \% \mathrm{CO}_{2}$. Cells were detached using $0.25 \%$ trypsin and subcultured at a ratio of 1:3. Cells were then seeded into 6 -well plates $\left(3 \times 10^{5}\right.$ cells/well). When the cells reached $70-80 \%$ confluence, they were considered to be in the logarithmic growth phase and were selected for subsequent experiments.

Cell grouping and transfection. Cells in the logarithmic growth phase were seeded into 6 -well plates $\left(2 \times 10^{5}\right.$ cells/well). When the cells had attached to the well and reached 30-60\% confluence they were transfected using Lipofectamine $2000^{\circledR}$ (cat. no. 11668-027; Invitrogen; Thermo Fisher Scientific, Inc.). Each transfection construct ( $50 \mathrm{nM}$; Shanghai GenePharma Co., Ltd.) was diluted using $250 \mu \mathrm{l}$ serum-free RPMI-1640 (Thermo Fisher Scientific, Inc.) medium, mixed and incubated at room temperature for $5 \mathrm{~min} ; 5 \mu 12000$ was prepared in a similar manner. Subsequently, the transfection constructs and 2000 were mixed and incubated at room temperature for $20 \mathrm{~min}$, prior to being added to the cells in the 6-well plates for $6 \mathrm{~h}$ at $37^{\circ} \mathrm{C}$ with saturated humidity and $5 \% \mathrm{CO}_{2}$. The medium containing the transfection solution was then replaced with RPMI-1640 media containing 10\% FBS at $37^{\circ} \mathrm{C}$ for $48 \mathrm{~h}$. Cells were divided into the following groups: i) Control group (U251MG or TJ905 cells receiving no treatment); ii) short hairpin RNA (sh)-negative control (NC) group (U251MG or TJ905 cells transfected with the pGPU6-sh-NC plasmid); iii) sh-LINC01138 group (U251MG or TJ905 cells transfected with the pGPU6-sh-LINC01138 plasmid, three shRNAs); iv) sh-LINC01138 + inhibitor-NC group (U251MG cells transfected with sh-LINC01138 and inhibitor-NC); and v) sh-LINC01138 + miR-375 inhibitor group (U251MG cells transfected with sh-LINC01138 and miR-375 inhibitor plasmids). All vectors were purchased from Shanghai GenePharma Co., Ltd., which inserted the shRNAs into the plasmids For 
each transfection, $1 \mu \mathrm{g}$ of each construct was added into each well. The sequences are shown in Table SI.

5-Ethynyl-2'-deoxyuridine (EdU) assay. Cells from each group were seeded into 96 -well plates $\left(4 \times 10^{3}\right.$ cells/well). The Cell-Light EdU Apollo488 In Vitro kit (cat. no. 100T; (Guangzhou RiboBio Co., Ltd.) was used to assess cell proliferation until the cells reached $80 \%$ confluence. Briefly, cells were incubated at $37^{\circ} \mathrm{C}$ for $2 \mathrm{~h}$ with $100 \mu \mathrm{l}$ RPMI-1640 medium $(50 \mu \mathrm{M}$ the EdU solution was diluted in medium at a ratio of 1:1,000). Cells were subsequently washed with phosphate-buffered saline (PBS) twice (5 min/wash), fixed using $50 \mu \mathrm{l} 4 \%$ paraformaldehyde at room temperature for $30 \mathrm{~min}$ and incubated with $50 \mu \mathrm{l}$ glycine $(2 \mathrm{mg} / \mathrm{ml})$ at room temperature for $5 \mathrm{~min}$. Cells were then washed with PBS for $5 \mathrm{~min}$, before being incubated with $100 \mu 10.5 \%$ Triton X-100 for $10 \mathrm{~min}$ at room temperature. Cells were once again washed with PBS for $5 \mathrm{~min}$. Subsequently, the cells were incubated with $100 \mu \mathrm{l} 1 \mathrm{X}$ Apollo ${ }^{\circledR}$ staining reaction solution in the dark for $30 \mathrm{~min}$ at room temperature $\left(25^{\circ} \mathrm{C}\right)$, permeated, and decolored with methyl alcohol. After the nuclei were stained with 4',6-diamidino-2-phenylindole at room temperature for $5 \mathrm{~min}$, the cells were observed under a confocal microscope (Leica Microsystems $\mathrm{GmbH}$ ).

Cell Counting Kit-8 (CCK-8) assay. U251MG or TJ905 cells were seeded into 96 -well plates $\left(1 \times 10^{3}\right.$ cells/well $)$ and incubated in $100 \mu \mathrm{l}$ medium containing $10 \% \mathrm{FBS}$. The cell proliferation was quantified after 24,48 and $72 \mathrm{~h}$ using a CCK-8 Kit (Dojindo Molecular Technologies, Inc.) according to the manufacturer's protocol. Briefly, $10 \mu \mathrm{l}$ CCK- 8 reagent was added to each well for $1 \mathrm{~h}$. The optical density was determined at $490 \mathrm{~nm}$ using a microplate reader.

Assessment of glucose uptake and lactate production. Glucose uptake was assessed as previously described (37). Briefly, U251MG or TJ905 cells were incubated at $35^{\circ} \mathrm{C}$ in Hank's balanced salt solution (HBSS; $137 \mathrm{mM} \mathrm{NaCl}, 5.36 \mathrm{mM} \mathrm{KCl}$, $1.26 \mathrm{mM} \mathrm{CaCl}_{2}, 0.41 \mathrm{mM} \mathrm{MgSO}_{4}, 0.49 \mathrm{mM} \mathrm{MgCl}_{2}, 0.63 \mathrm{mM}$ $\mathrm{Na}_{2} \mathrm{HPO}_{4} 7 \mathrm{H}_{2} \mathrm{O}, 0.44 \mathrm{mM} \mathrm{KH} \mathrm{PO}_{4}, 4.17 \mathrm{mM} \mathrm{NaHCO}$ and $5.55 \mathrm{mM}$ glucose; $\mathrm{pH}$ 7.2). The assay was initiated by the addition of $0.1 \mathrm{mM} \mu \mathrm{Ci} /$ well $\mathrm{D}-[3-3 \mathrm{H}]$ glucose. After $15 \mathrm{~min}$, the culture medium was removed and the cells were washed twice with cold HBSS to terminate the reaction. Cells were then lysed in a $0.5 \mathrm{M} \mathrm{NaOH}$ solution and analyzed using a scintillation counter (LS6500 Multipurpose Scintillation Counter; Beckman Coulter, Inc.). Each experiment was repeated three times.

Cell supernatant lactate levels were measured using a Lactate Colorimetric Assay kit (BioVision, Inc.). Briefly, cells $\left(5 \times 10^{5}\right.$ per dish) were seeded into $60-\mathrm{mm}$ culture dishes and incubated overnight in DMEM containing $10 \% \mathrm{FBS}$ at $37^{\circ} \mathrm{C}$. Subsequently, the medium was replaced with serum-free DMEM for 1-2 $\mathrm{h}$, the supernatant was collected, and the lactate levels were quantified using colorimetry according to the manufacturer's protocol.

Bioinformatics analysis. The TCGA data visualization website GEPIA (http://gepia.cancer-pku.cn/index.html) (38) was used to analyze the expression of LINC01138 and Sp1 in glioma $(n=163)$. The online prediction software, lncLocator, developed by the pattern recognition and bioinformatics research group of Shanghai Jiaotong University (http://www.csbio.sjtu. edu.cn/bioinf/lncLocator/) (39) was used to predict the subcellular localization of LINC01138, whereas the RNA22 tool (http://cm.jefferson.edu/rna22/Precomputed/) (40) was used to predict the binding sites of LINC01138 and miR-375. The TargetScan website (http://www.targetscan.org/vert_71/) (41) was used to predict the target gene of miR-375. The lncLocator and RNA22 software were used according to the default settings. The following FASTA files were obtained from GenBank (https://www.ncbi.nlm.nih.gov/): LINC01138 (accession no. NR_027468.3) and miR-375 (accession no. NR_029867.1).

Dual-luciferase reporter assay. Wild-type (WT) and mutant (MUT) miR-375 and SP1 3'-untranslated regions were synthesized and cloned into PmiR-RB-REPORT ${ }^{\mathrm{TM}}$ plasmids (Guangzhou RiboBio Co., Ltd.). NC plasmids (empty vectors) were used as a control. Following sequencing confirmation of the WT and MUT plasmids by Sangong Bioengineering (Shanghai) Co., Ltd., the $293 \mathrm{~T}$ cell line $\left(1 \times 10^{5}\right.$ cells/well in 24-well plates) was co-transfected with the WT or MUT plasmids $(50 \mathrm{nM})$ and the mimic-NC or miR-375 mimic $(50 \mathrm{nM})$ using Lipofectamine $2000^{\circledR}$. Following incubation for $48 \mathrm{~h}$ at $37^{\circ} \mathrm{C}$, cells were collected and lysed with ice-cold radioimmunoprecipitation assay (RIPA) lysis buffer (Beijing Solarbio Science \& Technology Co., Ltd.) containing $1 \mathrm{mmol} / 1 \mathrm{PMSF}$ ), followed by centrifugation for $3-5 \mathrm{~min}$ at $1,200 \mathrm{x} \mathrm{g} 4^{\circ} \mathrm{C}$. The cell supernatant was harvested to quantify relative luciferase units (RLUs) using the Firefly Luciferase Reporter Gene Assay Kit (cat. no. RG005; Beyotime Institute of Biotechnology) according to the manufacturer's protocol. The relative fluorescence values were obtained by dividing the RLU value of Firefly luciferase activity by that of Renilla luciferase activity. All experiments were repeated three times.

Subcellular fractionation localization. Following a previous method (42), nuclear and cytoplasmic components were separated using the PARIS ${ }^{\text {TM }}$ Kit (Thermo Fisher Scientific, Inc.). U251MG cells were harvested, washed with PBS, detached with trypsin, and centrifuged at $500 \mathrm{xg}$ at $4^{\circ} \mathrm{C}$ for $5 \mathrm{~min}$. The supernatant was discarded and the precipitates were washed using PBS and $500 \mu \mathrm{l}$ cell fractionation buffer added with gentle agitation. Cells were incubated on ice for 5-10 min and centrifuged at $500 \mathrm{x} \mathrm{g}$ at $4^{\circ} \mathrm{C}$ for $5 \mathrm{~min}$. The supernatant (cytoplasm) was transferred to a sterile nonenzymatic tube $(2 \mathrm{ml})$ and centrifuged at $500 \mathrm{x} \mathrm{g}$ at $4^{\circ} \mathrm{C}$ for $5 \mathrm{~min}$. The precipitates (nuclei) were added to $500 \mu \mathrm{l}$ cell fractionation buffer and mixed via gentle agitation before the addition of $500 \mu 12 \mathrm{X}$ lysis/binding solution and another gentle agitation at room temperature before being placed on ice for $5 \mathrm{~min}$. Cells were mixed with $500 \mu$ l precooled cell disruption buffer followed by $500 \mu 1$ absolute ethyl alcohol. An adsorption column was placed in the tube, $700 \mu 1$ reaction solution was added, and the tube was centrifuged at $4^{\circ} \mathrm{C}$ at $12,000 \mathrm{x}$ g for $30 \mathrm{sec}$; the solution in the tube was removed and these steps were repeated. Subsequently, $40 \mu 1$ elution solution was added and the samples were centrifuged at $4^{\circ} \mathrm{C}$ at $12,000 \mathrm{x} \mathrm{g}$ for $3 \mathrm{sec}$. A second elution step was performed using $10 \mu$ l elution 
solution. LINC01138 expression was detected by reverse transcription-quantitative PCR (RT-qPCR). GAPDH and U6 were used as cytoplasmic and nuclear internal reference genes, respectively.

RNA immunoprecipitation (RIP) assay. Following the manufacturer's instructions, Magna RIP ${ }^{\mathrm{TM}}$ RNA-Binding Protein Immunoprecipitation Kit (cat. no. 17-700; Merck KGaA) was used to determine the binding relationship between LINC01138, miR-375 and Ago2. Glioma cells (U251MG, $1.0 \times 10^{7}$ cells) were washed with precooled PBS to remove media. Cells were then lysed with ice-cold radioimmunoprecipitation assay (RIPA) lysis buffer (Beijing Solarbio Science \& Technology Co., Ltd.; RIPA containing $1 \mathrm{mmol} / 1$ PMSF) and centrifuged at $230,000 \mathrm{x} \mathrm{g}$ at $4^{\circ} \mathrm{C}$ for $10 \mathrm{~min}$ to remove the supernatant. Co-precipitation was performed by washing and resuspending $50 \mu \mathrm{l}$ magnetic beads from each co-precipitation reaction system in $100 \mu \mathrm{l}$ RIP wash buffer, before adding $5 \mu \mathrm{g}$ antibody and incubating for $30 \mathrm{~min}$ at room temperature. The bead-antibody complexes were washed and resuspended in $900 \mu \mathrm{l}$ RIP wash buffer, and $100 \mu \mathrm{l}$ cell extraction solution was added and incubated overnight at $4^{\circ} \mathrm{C}$. Samples were placed on a magnetic seat to collect the bead-protein complexes. RNA was extracted from the samples following proteinase $\mathrm{K}$ detachment and used for subsequent RT-qPCR. The antibodies used in the RIP assays were rabbit anti-Ago2 (1:50; cat. no. ab186733; Abcam) and the NC rabbit anti-immunoglobulin G (IgG) (1:100; cat. no. ab109489; Abcam). Each experiment was repeated three times.

RNA pull-down assay. Cells were transfected with $50 \mathrm{nM}$ biotin-labeled WT- miR-375 and MUT-miR-375 (Wuhan Genecreate Bioengineering Co., Ltd.). Following $48 \mathrm{~h}$ of incubation at $37^{\circ} \mathrm{C}$, the cells were harvested, washed with PBS and incubated in specific lysis buffer (800 $\mu \mathrm{l}$; Ambion; Thermo Fisher Scientific, Inc.) for at $4^{\circ} \mathrm{C} 10 \mathrm{~min}$. After centrifugation at $20,000 \mathrm{xg}$ at $4^{\circ} \mathrm{C}$ for $10 \mathrm{~min}$, the supernatant was collected. The lysate was incubated with M-280 MagneSphere/Streptavidin beads $\left(50 \mu \mathrm{l} ; 6 \times 10^{8}\right.$ magnetic beads $/ \mathrm{ml}$; cat. no. 60210 ; Invitrogen; Thermo Fisher Scientific, Inc.) precoated with RNase-free bovine serum albumin (0.1\% BSA) and the enzyme tRNA (TRNABAK-RO; MilliporeSigma), and incubated at $4^{\circ} \mathrm{C}$ overnight. Subsequently, the magnetic beads were collected on the magnetic frame and the supernatant was removed the beads were washed twice with precooled lysis buffer $(800 \mu \mathrm{l})$, three times with low-salt buffer $(800 \mu \mathrm{l}$; $0.1 \mathrm{M} \mathrm{NaOH}$ and $0.05 \mathrm{M} \mathrm{NaCl}$ ) and once with high-salt buffer (800 $\mu \mathrm{l} ; 0.1 \mathrm{M} \mathrm{NaCl})$. Following washing, the magnetic beads were collected on the magnetic frame and the supernatant was removed and the beads were resuspended in the low-salt buffer. Following extraction of the bound RNA using TRIzol ${ }^{\circledR}$ (Invitrogen; Thermo Fisher Scientific, Inc.), LINC01138 enrichment was assessed via RT-qPCR. All experiments were repeated three times.

$R T$ - $q P C R$. Total RNA was extracted from cells and tissues using TRIzol reagent. The RNA concentration and purity were determined, and the extracted total RNA was reverse transcribed into cDNA using the RevertAid First Strand cDNA Synthesis Kit (cat. no. K1621; Thermo Fisher Scientific, Inc.) according to the manufacturer's protocol. The qPCR primers (Shanghai Genechem Co., Ltd.) specific for LINC01138, miR-375 and SP1 are shown in Table I. Premix Ex Taq Probe qPCR; Takara Biotechnology Co., Ltd.) was performed to assess the expression levels of each gene. Each qPCR reaction contained: $5.3 \mu \mathrm{l} 2 \mathrm{X}$ Taq Master Mix, $1 \mu \mathrm{l}$ forward primer $(5 \mu \mathrm{M}), 1 \mu \mathrm{l}$ reverse primer $(5 \mu \mathrm{M}), 1 \mu \mathrm{l}$ cDNA and $11.7 \mu \mathrm{l}$ RNase-free H2O. The following thermocycling conditions were used for qPCR: Expression levels were quantified using a qPCR instrument (Applied Biosystems 7500; Applied Biosystems Thermo Fisher Scientific, Inc.). mRNA expression levels were quantified using the $2^{-\Delta \Delta \mathrm{Cq}}$ method (43) and normalized to the internal reference genes; U6 for miR-375, and GAPDH for LINC01138 and SP1. All the experiments were repeated three times.

Western blotting. Protein expression levels were determined via western blotting. To extract total protein, tissues were harvested and placed in centrifuge tubes, $100 \mu \mathrm{l}$ RIPA lysis solution was added (Beijing Solarbio Science \& Technology Co., Ltd.; RIPA containing $1 \mathrm{mmol} / 1 \mathrm{PMSF}$ ), and the samples were centrifuged at $4^{\circ} \mathrm{C}$ at $11,000 \mathrm{x}$ g for 20 min until fully lysed. After lysis the tissues were incubated on ice for $30 \mathrm{~min}$ at $4^{\circ} \mathrm{C}$ and centrifuged at $12,000 \mathrm{x}$ g for $4 \mathrm{~min}$ at $4^{\circ} \mathrm{C}$. The supernatant was then extracted and stored at $-80^{\circ} \mathrm{C}$. Total protein was quantified using a BCA Protein Assay Kit (Boster Biological Technology), and was adjusted to $3 \mu \mathrm{g} / \mu \mathrm{l}$. The extracted proteins were boiled with loading buffer at $95^{\circ} \mathrm{C}$ for $10 \mathrm{~min}$, and $30 \mu \mathrm{g}$ protein/lane was separated by SDS-PAGE on a $10 \%$ gel (Beyotime Institute of Biotechnology). The separated proteins were subsequently transferred onto a polyvinylidene fluoride membrane (MilliporeSigma) and blocked with 5\% BSA (Invitrogen; Thermo Fisher Scientific, Inc.) for $1 \mathrm{~h}$ at room temperature. The membranes were incubated with primary antibodies against the following: HK (1:1,000; cat. no. ab209847; Abcam), PK (1:1,000; cat. no. ab32566; Abcam), PFK (1:2,000; cat. no. ab204131; Abcam), GLUT (1:100,000; cat. no. ab115730; Abcam), SP1 (1:10,000; cat. no. ab231778; Abcam) and GAPDH (1:10,000; cat. no. ab181602; Abcam) at $4^{\circ} \mathrm{C}$ overnight. Membranes were washed with Tris-buffered saline-Tween-20 (0.05\%) three times ( $5 \mathrm{~min} /$ wash). Following the primary antibody incubation, membranes were incubated with the corresponding goat anti-rabbit HRP-labelled secondary antibody (1:2,000; cat. no. ab6721; Abcam) for $1 \mathrm{~h}$ at room temperature. Membranes were subsequently washed three times (5 min/wash). Protein bands were visualized by enhanced chemiluminescence Pierce ${ }^{\mathrm{TM}}$ ECL Western Blotting Substrate (cat. no. 32209; Thermo Fisher Scientific, Inc.). A Bio-Rad Gel Dol EZ imager (Bio-Rad Laboratories, Inc.) was used for band development. The gray values of the target bands were semi-quantified using ImageJ (version 1.48; National Institutes of Health) with GAPDH as the loading control.

Xenograft tumors in nude mice. A total of 16 female BALB/c nude mice (age, 3-4 weeks; weight, 14-18 g; Nanjing Junke Biological Engineering Co., Ltd.) were raised in a specific pathogen-free environment at $18-22^{\circ} \mathrm{C}$, with a humidity of 50-60\% under a 12-h light/dark cycle and fed sterile food. All mice had free access to food and water. The mice were 
Table I. Sequences of primers used for reverse transcriptionquantitative PCR.

\begin{tabular}{ll} 
Gene & \multicolumn{1}{c}{ Sequence (5'-3') } \\
\hline LINC01138 & F: ACATCGTGAGCACATTTGAGA \\
& R: TCTTGCTGTTCAGGGTGGTA \\
miR-375 & F: TCGCACAAACGTCGTATCCA \\
& R: GTATCCAGTGCGTGTCGTGG \\
SP1 & F: TTGAAAAAGGAGTTGGTGGC \\
& R: TGCTGGTTCTGTAAGTTGGG \\
U6 & F: CGCTTCACGAATTGCGTGTCAT \\
& R: GCTTCGGCAGCACATATACTAAAAT \\
GAPDH & F: TCCCATCACCATCTTCCA \\
& R: CATCACGCCACAGTTTCC
\end{tabular}

LINC, long intergenic non-protein coding RNA; miR, microRNA; $\mathrm{SP} 1$, specificity protein $1 ; \mathrm{F}$, forward; $\mathrm{R}$, reverse.

randomly divided into the sh-NC group (mice injected with U251MG cells stably transfected with sh-NC) and the sh-LINC01138 group (mice injected with U251MG cells stably transfected with sh-LINC01138). After skin disinfection, each mouse was injected with $0.2 \mathrm{ml}$ cell suspension $\left(1.0 \times 10^{6}\right.$ cells $)$ via the axilla (44). The general behavior of the mice and the condition of the local injection site were observed. Tumor volume (V) was assessed using Vernier calipers every other week, and was calculated as $\mathrm{V}=$ length $\mathrm{x}$ width ${ }^{2} \mathrm{x} 0.5$ (42). Mice were euthanized through excessive administration of sodium pentobarbital $(100 \mathrm{mg} / \mathrm{kg})$ after $\sim 6$ weeks. Following euthanasia, tumors were extracted and quantified. The humane endpoints of the study were when the mice experienced weight loss of $>15 \%$ of their total weight, or mice suffered from tumor load. In the present study, when the maximum tumor length and width were as follows: Tumor length, $1.55 \mathrm{~cm}$; and width, $1.12 \mathrm{~cm}$, the mice were sacrificed.

Immunohistochemical staining. Tumor tissues from each group of mice were washed and dehydrated in 70,80 and 90\% ethanol solution. Then, the tissues were placed in the same amount of mixed pure alcohol and xylene for $15 \mathrm{~min}$ and in xylene I and xylene II for 15 min each until clear followed by mixed solution of xylene and paraffin in equal amount for $15 \mathrm{~min}$ and in paraffin I and II for 50-60 min each. Next, the tissues were paraffin-embedded and sliced at $5 \mu \mathrm{m}$, warmed, dewaxed and dehydrated. All operating temperatures are room temperature and reagents are from Sigma. Sections were washed with running water for $2 \mathrm{~min}$, incubated in $3 \% \mathrm{H}_{2} \mathrm{O}_{2}$-methyl alcohol for $20 \mathrm{~min}$, washed with distilled water for $2 \mathrm{~min}$ and washed with $0.1 \mathrm{M}$ PBS for $3 \mathrm{~min}$. Sections were recovered in in a water bath $\left(95-100^{\circ} \mathrm{C}\right)$ in the antigen retrieval solution (1 mM EDTA; $\mathrm{pH}$ 8.0), cooled in running water, and incubated with normal goat serum sealant (Shanghai Haoran Biotechnology Co., Ltd.) at room temperature for $20 \mathrm{~min}$. When the sections had dried, they were incubated with primary antibodies targeting SP1 (1:1,000: cat. no. ab231778; Abcam) at $4^{\circ} \mathrm{C}$ overnight. Sections were washed three times in $0.1 \mathrm{M}$ PBS (5 min/wash) and were incubated with goat anti-rabbit $\operatorname{IgG}(1: 2,000$ : cat. no. ab6721; Abcam) secondary antibody at $37^{\circ} \mathrm{C}$ for $20 \mathrm{~min}$. Sections were washed three times in PBS (5 min/wash) and were incubated with a HRP-labeled streptavidin working solution (Imunbio Biotechnology Co., Ltd.) at $37^{\circ} \mathrm{C}$ for $20 \mathrm{~min}$. Subsequently, sections were subjected to three washes in PBS (5 min/wash), stained by DAB at room temperature for 2 min (Guangzhou Whiga Technology Co., Ltd.), washed with running water, counterstained with hematoxylin (Shanghai Bogoo Biological Technology Co., Ltd.) for $1 \mathrm{~min}$ at room temperature, washed with running water and reversed to blue staining with $1 \%$ ammonium hydroxide, followed by another wash in running water. Sections were dehydrated with an ascending ethanol series, treated with xylene, sealed with neutral resin and observed under a light microscope. To determine the number of positive cells in each field, five high-power fields were randomly chosen from each section (45).

Statistical analysis. SPSS version 21.0 (IBM Corp.) was used for data analysis. All experiments were repeated 3 times. Data are presented as the mean \pm standard deviation. The data were normally distributed. Student's t-test was used for comparisons between two groups, whereas one-way or two-way analysis of variance (ANOVA) was used for comparisons among more than two groups, followed by Tukey's post hoc multiple comparisons test. $\mathrm{P}<0.05$ was considered to indicate a statistically significant difference.

\section{Results}

LINC01138 is highly expressed in human glioma tissues and cells, with high expression being associated with clinicopathological features. Analysis of LINC01138 expression in human glioma tissue using The Cancer Genome Atlas revealed that LINC01138 was markedly more highly expressed compared with that in healthy tissue (Fig. 1A). In the present study, LINC01138 expression was detected in the glioma tissues and adjacent normal tissues of 108 patients with glioma. The RT-qPCR results demonstrated that LINC01138 expression levels were significantly higher in glioma tumor tissues compared with those in adjacent normal tissues (Fig. 1B; $\mathrm{P}<0.05)$. Furthermore, LINC01138 expression levels were significantly elevated in human glioma cell lines compared with those in NHAs (Fig. 1C; $\mathrm{P}<0.05$ ). Analysis of the relationship between LINC01138 expression and the clinicopathological features of patients with glioma indicated that LINC01138 expression was not associated with the age and sex of patients $(\mathrm{P}>0.05)$, but was associated with WHO tumor grade, lymph node metastasis and tumor diameter (all $\mathrm{P}<0.05$; Table II).

Silencing LINC01138 inhibits glioma cell proliferation. To determine the role of LINC01138 in glioma cell proliferation, three sh-LINC01138 plasmids were constructed and transfected into U251MG and TJ905 cells, which expressed high levels of LINC01138. The sh-plasmids significantly reduced LINC01138 expression. sh-LINC01138-2 exhibited the highest silencing efficiency and was therefore selected for further experiments (Fig. 2A). The proliferation of U251MG and TJ905 cells with sh-LINC01138 was determined using CCK-8 and EdU assays. The results demonstrated that proliferation was 


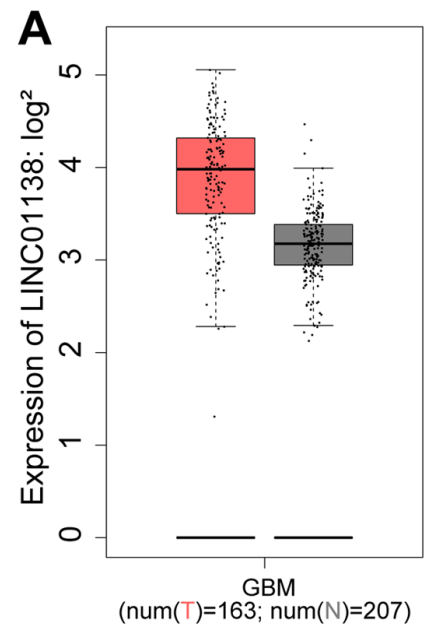

B

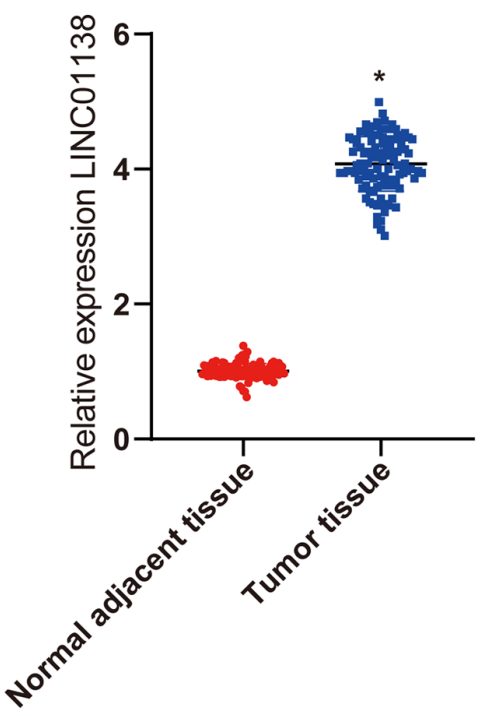

C

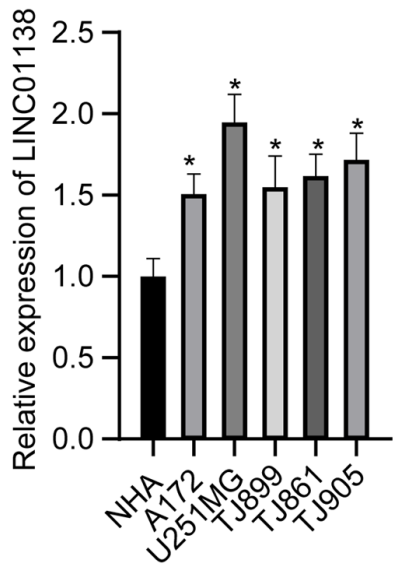

Figure 1. LINC01138 is highly expressed in human glioma tissues and cells, which is associated with the clinicopathological features of the tumor. (A) LINC01138 expression data in human glioma tissues from The Cancer Genome Atlas database, red represents tumor and grey normal tissue, LINC01138 is significantly highly-expressed in glioma. (B) LINC01138 expression levels in human brain glioma tissues and adjacent normal tissues ( $\mathrm{n}=108$ ) was detected by RT-qPCR. ${ }^{*}$ P<0.05 vs. normal adjacent tissue (paired Student's t-test). (C) LINC01138 expression levels in human brain glioma cells was verified by RT-qPCR. Independent cell experiments were conducted 3 times. " $\mathrm{P}<0.05$ vs. NHAs (one-way ANOVA and Tukey's multiple comparisons test). Data are presented as the mean \pm SD. LINC, long intergenic non-protein coding RNA; RT-qPCR, reverse transcription-quantitative PCR; NHAs, normal human astrocytes; num(T), number of tumor tissue samples; num(N), number of normal adjacent tissue samples; GBM, glioblastoma.

Table II. LINC01138 expression and clinicopathological features of patients with glioma.

\begin{tabular}{lcc}
\hline $\begin{array}{l}\text { Clinicopathological } \\
\text { parameters }\end{array}$ & $\begin{array}{c}\text { LINC01138 relative } \\
\text { expression levels }\end{array}$ & P-value \\
\hline Age, years & & $>0.05$ \\
$\quad<50$ & $4.10 \pm 0.41$ & \\
$\geq 50$ & & $>0.05$ \\
Sex & $4.02 \pm 0.39$ & \\
Male & $4.14 \pm 0.42$ & \\
Female & & $<0.05$ \\
WHO grading & $3.60 \pm 0.28$ & \\
I+II & $4.24 \pm 0.30$ & $<0.05$ \\
III+IV & & \\
Lymph node metastasis & $4.23 \pm 0.31$ & \\
Yes & $3.76 \pm 0.40$ & \\
No & & \\
Tumor diameter & $3.72 \pm 0.37$ & \\
$\leq 5 \mathrm{~cm}$ & $4.24 \pm 0.31$ & \\
$>5 \mathrm{~cm}$ & & \\
\hline
\end{tabular}

LINC, long intergenic non-protein coding RNA; WHO, World Health Organization.

significantly reduced in sh-LINC01138-transfected U251MG and TJ905 cells compared with that in sh-NC-transfected cells (Fig. 2B and $\mathrm{C}$; all $\mathrm{P}<0.05$ ), suggesting that silencing LINC01138 inhibited human glioma cell proliferation.
Silencing LINC01138 inhibits aerobic glycolysis in glioma cells. To identify the effect of LINC01138 on aerobic glycolysis in glioma cells, cell glucose uptake and lactic acid secretion were analyzed. The results demonstrated that both glucose uptake and lactic acid secretion by U251MG and TJ905 cells were significantly reduced by sh-LINC01138 compared with sh-NC (Fig. 3A and $\mathrm{B} ; \mathrm{P}<0.05$ ). The ratio between glucose uptake and lactic acid secretion was 1:2 during glycolysis $(46,47)$. Lactic acid secretion was used to calculate the proportion of the total glucose taken up by cells that was consumed by glycolysis. The results indicated that the amount of glucose consumed by glycolysis, relative to the total glucose taken up by the cells, was significantly decreased in the sh-LINC01138 group compared with that in the sh-NC group (Fig. 3C; $\mathrm{P}<0.05$ ). Moreover, the expression levels of glycolysis-associated enzymes, including HK, PK, PFK and GLUT, were detected via western blotting. The results demonstrated that HK, PK, PFK and GLUT protein expression levels were all significantly reduced in the sh-LINC01138 group compared with those in the sh-NC group (Fig. 3D; $\mathrm{P}<0.05$ ). These data indicated that silencing LINC01138 could aberrantly induce aerobic glycolysis in human glioma cells.

LINC01138 modulates miR-375 by acting as a ceRNA. To further investigate the function of LINC01138, its subcellular localization was predicted using lncLocator (39). LINC01138 was determined to be mainly localized to the cytoplasm (Fig. 4A). Analysis of the RNA in nuclear and cytoplasmic fractions demonstrated LINC01138 was principally distributed in the cytoplasm of U251MG (Fig. 4B) and TJ905 cells (data not shown). These results suggested that LINC01138 served a role in glioma via the ceRNA network 

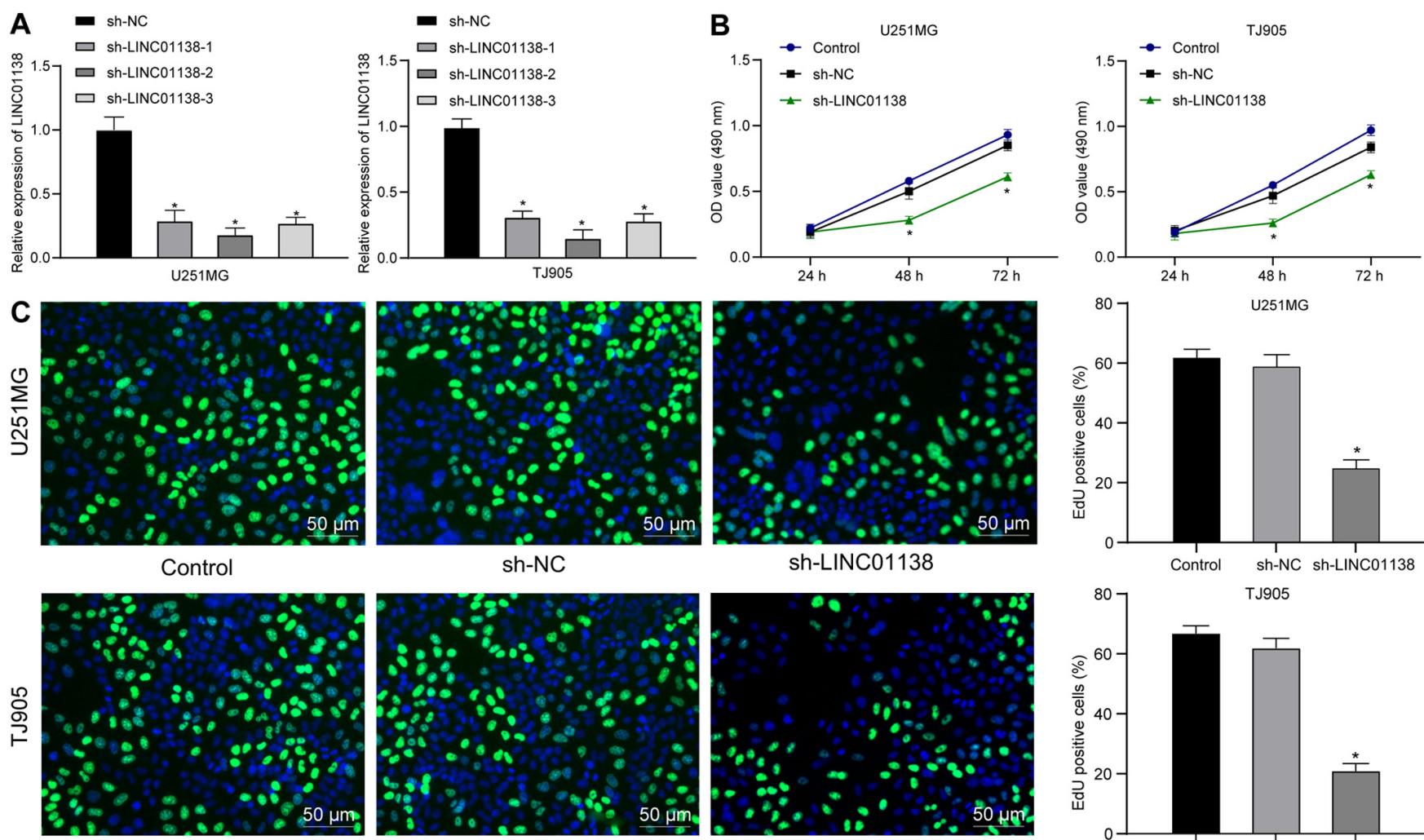

Sh-LINC01138
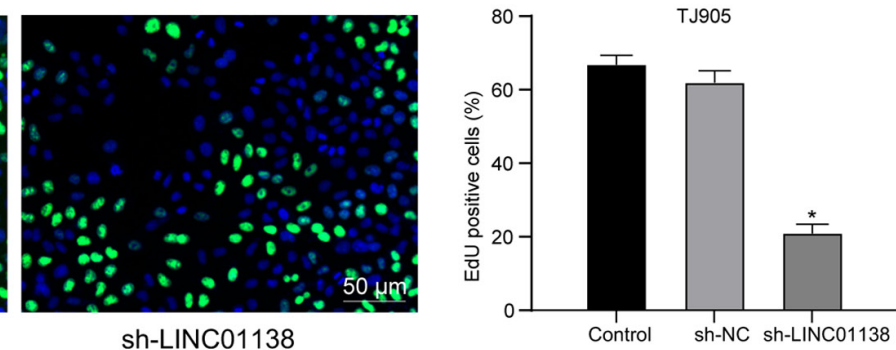

Figure 2. Silencing LINC01138 inhibits human glioma cell proliferation. (A) sh-LINC01138 efficiency in U251MG and TJ905 cells was verified by reverse transcription-quantitative PCR. sh-LINC01138-2 was the most efficient sequence and was chosen for further experiments. U251MG and TJ905 cell proliferation after LINC01138 silencing was detected using the (B) Cell Counting Kit-8 and (C) EdU assays. Independent cell experiments were conducted 3 times. Data are presented as the mean $\pm \mathrm{SD}$. " $\mathrm{P}<0.05$ vs. sh-NC (one-way ANOVA and Tukey's multiple comparisons test). LINC, long intergenic non-protein coding RNA; sh, short hairpin RNA; NC, negative control; OD, optical density.
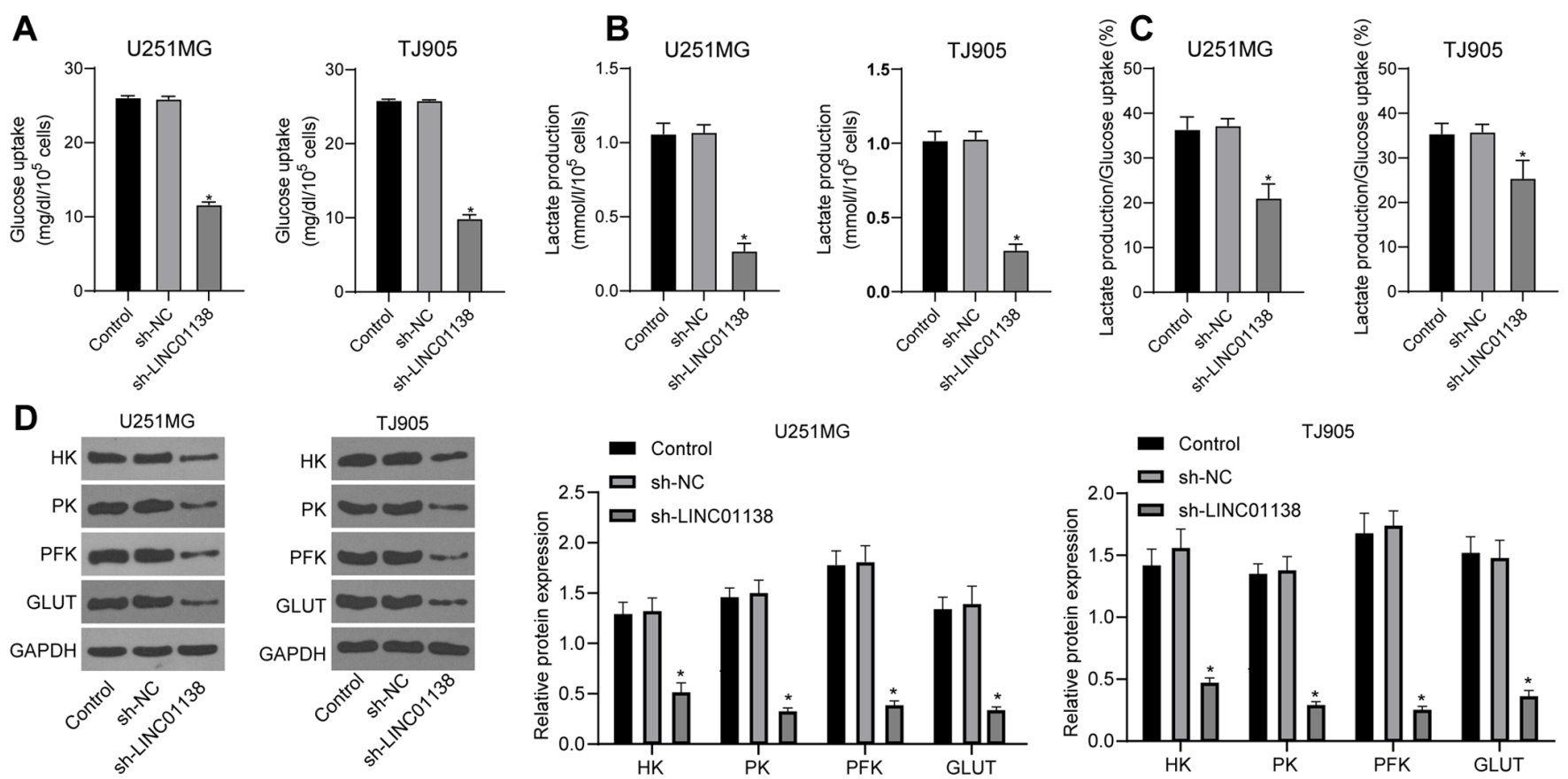

Figure 3. Silencing LINC01138 inhibits aerobic glycolysis in human glioma cells. (A) Glucose uptake and (B) lactic acid secretion in U251MG and TJ905 cells after LINC01138 silencing was detected by scintillation counter and lactic acid detection kit. (C) Ratio of glucose consumption in the glycolysis pathway in U251MG and TJ905 cells following silencing of LINC01138. "P<0.05 vs. sh-NC (one-way ANOVA and Tukey's multiple comparisons test). (D) Glycolysis-associated protein expression levels in U251MG and TJ905 cells following LINC01138 silencing was verified by western blotting. Independent cell experiments were conducted 3 times. Data are presented as the mean $\pm \mathrm{SD}$. " $\mathrm{P}<0.05$ vs. sh-NC (one-way ANOVA and Tukey's multiple comparisons test). LINC, long intergenic non-protein coding RNA; sh, short hairpin RNA; NC, negative control; HK, hexokinase; PK, pyruvate kinase; PFK, phosphofructokinase; GLUT, glucose transporter. 
A

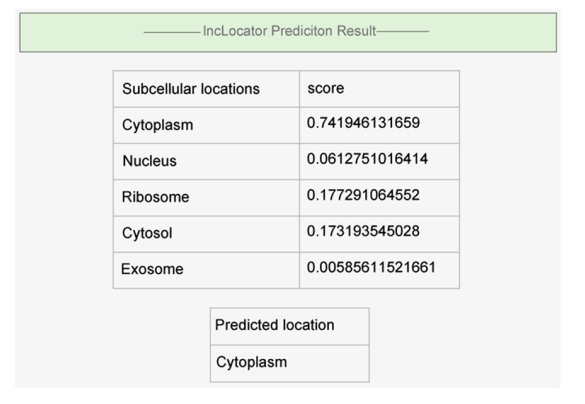

B

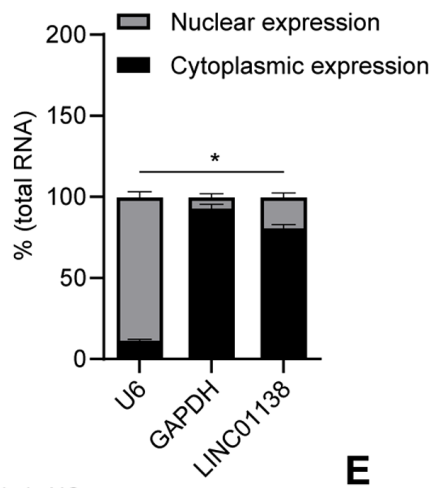

C

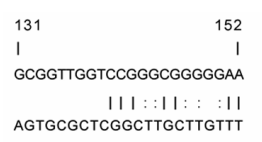

AGTGCGCTCGGCTTGCTTGITT
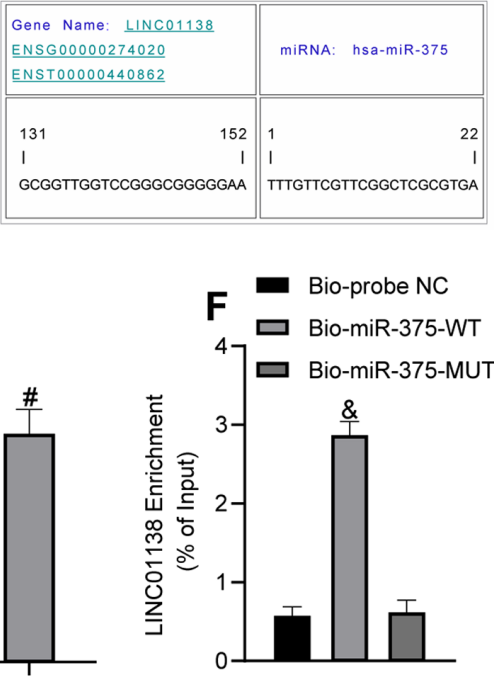

G

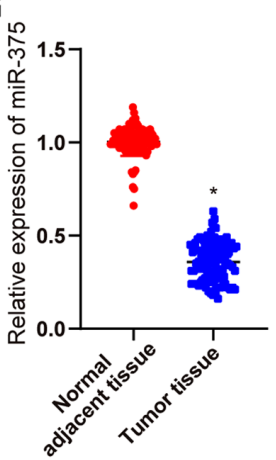

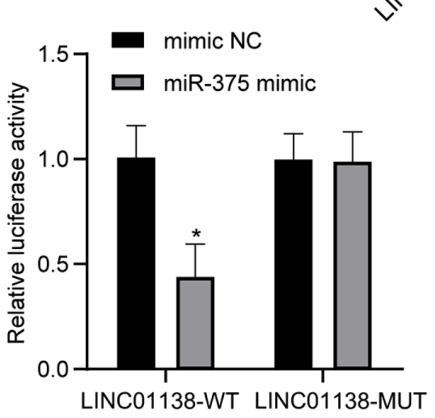

H

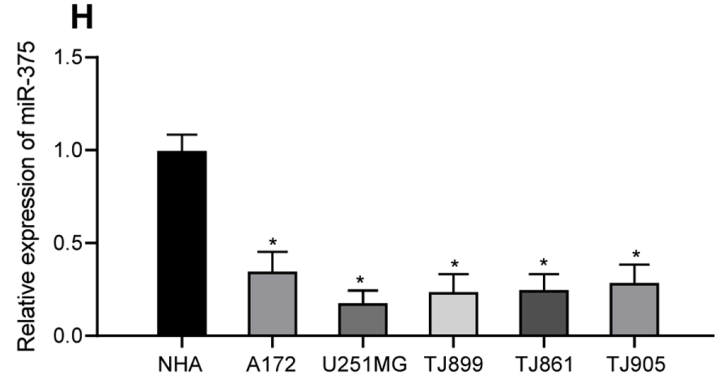

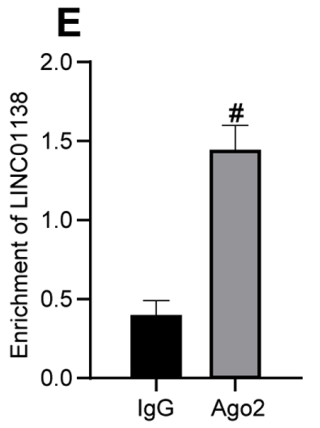

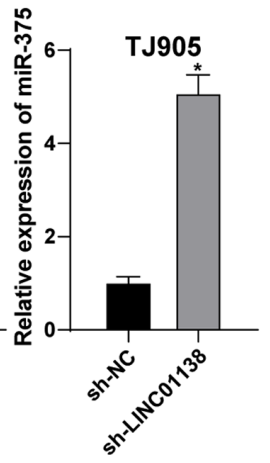

Figure 4. LINC01138 modulates miR-375 by acting as a competing endogenous RNA. (A) LINC01138 subcellular localization was predicted using lncLocator software. (B) LINC01138 subcellular localization in U251MG cells was verified by the fractionation of nuclear and cytoplasmic RNA, with GAPDH as the cytoplasmic marker and U6 as the nuclear marker. * $\mathrm{P}<0.05$ vs. U6 expressed in the cytoplasm. (C) LINC01138 and miR-375 binding site was predicted by the bioinformatics software RNA22. (D) LINC01138 and miR-375 binding site was confirmed using the dual-luciferase reporter assay. ${ }^{*} \mathrm{P}<0.05$ vs. mimic-NC. (E) The LINC01138 and miR-375 binding relationship was detected by RNA immunoprecipitation. ${ }^{\#} \mathrm{P}<0.05$ vs. IgG. (F) Binding of miR-375 to LINC01138 was confirmed by RNA pull-down assay. ${ }^{\&} \mathrm{P}<0.05$ vs. Bio-probe NC. (G) miR-375 expression levels in human glioma tissues and adjacent normal tissues $(\mathrm{n}=108)$ was verified by RT-qPCR. "P<0.05 vs. normal adjacent tissues. (H) miR-375 expression levels in human glioma cell lines was determined by RT-qPCR. ${ }^{*} \mathrm{P}<0.05$ vs. NHAs. (I) miR-375 expression levels in U251MG and TJ905 cells following LINC01138 silencing was detected by RT-qPCR. *P<0.05 vs. sh-NC. Data were analyzed using (B and D) two-way ANOVA and Tukey's multiple comparisons test; (E, G and I) independent samples t-test; and (F and H) one-way ANOVA and Tukey's multiple comparisons test. Independent cell experiments were conducted three times. Data are presented as the mean \pm SD. LINC, long intergenic non-protein coding RNA; miR, microRNA; NC, negative control; RT-qPCR, reverse transcription-quantitative PCR; NHA normal human astrocyte; sh, short hairpin RNA; WT, wild-type; MUT, mutant.

by competitively binding to miRNA. RNA22, a miRNA target discovery tool, predicted that there was a binding site between LINC01138 and miR-375 (Fig. 4C). Furthermore, the dual-luciferase reporter assay confirmed that, compared with in the mimic NC group, the miR-375 mimic group exhibited significantly decreased luciferase activity following transfection with LINC01138-WT. Luciferase activity following transfection with LINC01138-MUT and the miR-375 mimic did not change compared with the mimic NC (Fig. 4D). The RIP assay (Fig. 4E) demonstrated the Ago2-targeted antibody precipitated LINC01138 and miR-375 at significantly higher levels compared with IgG, indicating the binding of LINC01138 and miR-375. Furthermore, compared with the Bio-probe NC group, the RNA pull-down assay (Fig. 4F) demonstrated that the Bio-miR-375-WT group had significantly increased LINC01138 expression levels, whereas the Bio-miR-375-MUT group showed no marked difference in expression. These results suggested that miR-375 could possibly directly bind to LINC01138. The RT-qPCR results demonstrated that miR-375 expression levels were significantly lower in glioma tissues compared with those in adjacent normal tissues (Fig. 4G; $\mathrm{P}<0.05)$. miR-375 was also expressed at significantly lower levels in human glioma cell lines compared with in NHAs (Fig. 4H; P<0.05). Furthermore, miR-375 expression in U251MG and TJ905 cells in which LINC01138 was knocked down was measured by RT-qPCR. Compared with in the sh-NC group, the sh-LINC01138 group exhibited significantly elevated miR-375 expression levels (Fig. 4I; P<0.05). Overall, 

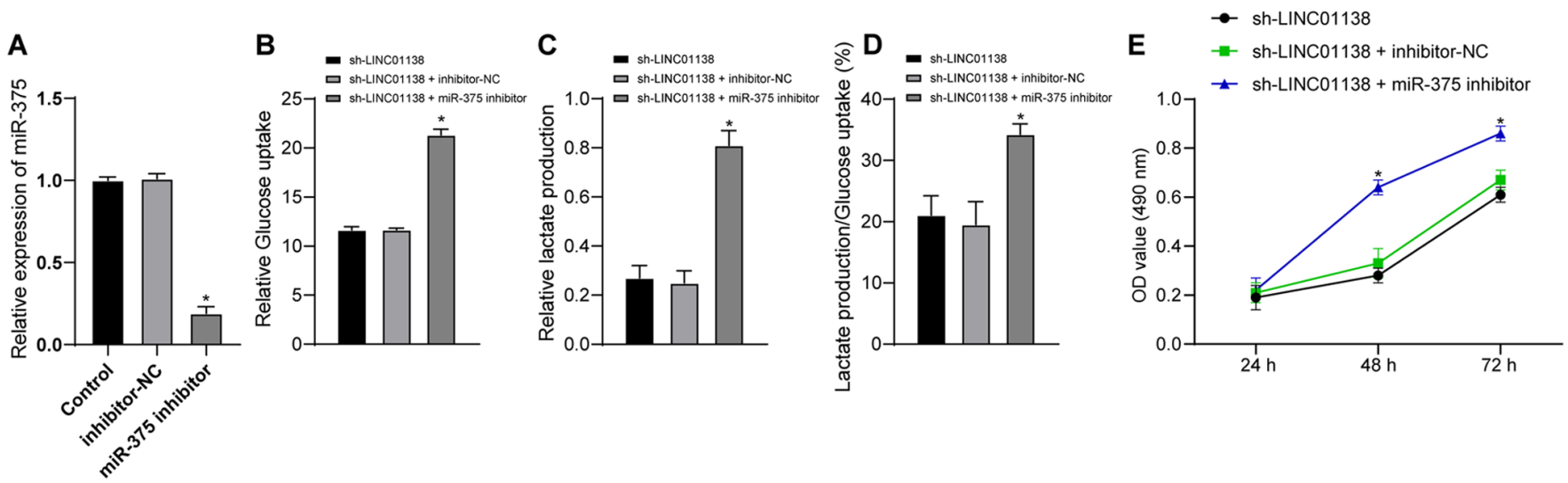

Figure 5. miR-375 inhibition reverses the effect of LINC01138 knockdown on aerobic glycolysis and cell proliferation in human glioma. (A) Transfection efficiency of the miR-375 inhibitor was verified by reverse transcription-quantitative PCR. (B) Glucose uptake and (C) lactic acid secretion in U251MG cells were assessed by the scintillation counter and lactic acid detection kit. (D) Ratio of glucose consumption in the glycolysis pathway. (E) U251MG cell proliferation was detected by the Cell Counting Kit-8 assay. Independent cell experiments were conducted 3 times. Data are presented as the mean \pm standard deviation. "P<0.05 vs. sh-LINC01138. Data were analyzed using (A-D) one-way ANOVA and Tukey's multiple comparisons test; and (E) two-way ANOVA and Tukey's multiple comparisons test. miR, microRNA; LINC, long intergenic non-protein coding RNA; sh, short hairpin RNA; NC, negative control; OD, optical density; HK, hexokinase.

LINC01138 may competitively bind to miR-375 to inhibit miR-375 expression in glioma.

miR-375 downregulation reverses the role of LINC01138 silencing in promoting aerobic glycolysis and cell proliferation in human glioma. To further investigate whether LINC01138 could regulate the function of glioma cells via miR-375, a functional rescue assay was conducted. U251MG cells were divided into the sh-LINC01138 group, the sh-LINC01138+ inhibitor-NC group and the sh-LINC01138 + miR-375-inhibitor group. The transfection efficiency of miR-375 inhibitor was verified by RT-qPCR. Inhibitor NC had no effect on the expression of miR-375 in cells, but miR-375 inhibitor significantly decreased the expression of miR-375 in cells compared with inhibitor NC (Fig. 5A; $\mathrm{P}<0.05$ ). Compared with in the sh-LINC01138 group, the sh-LINC01138 + miR-375-inhibitor group exhibited significantly increased glucose uptake and lactic acid secretion, and a significantly increased proportion of glucose consumed in glycolysis relative to the total glucose uptake (Fig. 5B-D; P<0.05). The CCK-8 assay demonstrated that the miR-375 inhibitor significantly reversed the inhibitory effect of sh-LINC01138 on glioma cell proliferation compared with the sh-LINC01138 group (Fig. 5E; $\mathrm{P}<0.05$ ). These findings indicated that miR-375 inhibition reversed the effect of sh-LINC01138 on inhibiting abnormal aerobic glycolysis and cell proliferation in human glioma.

LINC01138 can promote SP1 expression by competing with SP1 for binding to miR-375. SP1 expression in human glioma tissues from TCGA was analyzed; the results demonstrated that SP1 was significantly more highly expressed in human glioma compared with that in healthy tissue (Fig. 6A; $\mathrm{P}<0.05$ ). TargetScan predicted that there was a binding site between miR-375 and SP1 (Fig. 6B). The dual-luciferase reporter assay (Fig. 6C) demonstrated that compared with the mimic NC group, the luciferase activity in the binding region of SP1-WT and miR-375 in the miR-375 mimic group was inhibited, but there was no significant difference in the luciferase activity of
SP1-MUT, indicating that miR-375 could specifically bind to $\mathrm{SP} 1(\mathrm{P}<0.05)$. It was therefore hypothesized that LINC01138 might act as a ceRNA, sponging miR-375 to upregulate SP1 expression and eventually exacerbate the malignancy of glioma. To confirm this hypothesis, RT-qPCR was conducted to assess SP1 mRNA expression levels in both human glioma tissues and adjacent normal brain tissues. Compared with those in adjacent normal tissues and normal cells, glioma tissues and cells displayed significantly elevated SP1 mRNA expression levels (Fig. 6D and E; P<0.05). RT-qPCR and western blotting demonstrated that SP1 mRNA and protein expression levels in U251MG cells in the sh-LINC01138 group were significantly lower than those in the sh-NC group. Furthermore, SP1 mRNA and protein expression levels were recovered in the sh-LINC01138 + miR-375-inhibitor group compared with those in the sh-LINC01138 + inhibitor-NC group (Fig. 6F and G; $\mathrm{P}<0.05$ ). In summary, LINC01138 may function as a ceRNA to sponge and suppress miR-375 expression thus increasing SP1 expression.

Silencing LINC01138 inhibits tumor growth in vivo. To verify the function of LINC01138 in glioma tumor formation, a xenograft tumor model was established in nude mice. Compared with in the sh-NC group, the sh-LINC01138 group exhibited significantly reduced tumor growth and weight (Fig. 7A-C; $\mathrm{P}<0.05)$. RT-qPCR demonstrated that the expression levels of both LINC01138 and SP1 were significantly downregulated in the sh-LINC01138 group compared with those in the sh-NC group. Moreover, the expression levels of miR-375 were significantly upregulated in the sh-LINC01138 group compared with those in the sh-NC group (Fig. 7D; P<0.05). SP1 protein expression levels in glioma tissues were evaluated by immunohistochemical staining. The results demonstrated that SP1 protein expression levels were significantly lower in the sh-LINC01138 group compared with those in the sh-NC group (Fig. 7E; $\mathrm{P}<0.05$ ). These findings indicated that silencing LINC01138 inhibited glioma growth in vivo by regulating the miR-375/SP1 axis. 


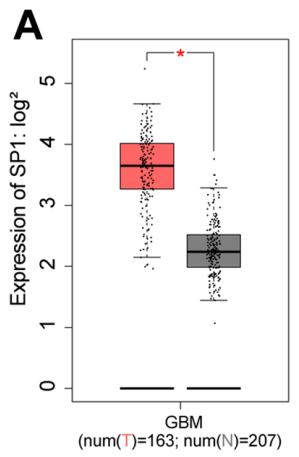

C

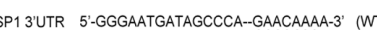

miR-375 3-AGTGCGCTCGGCTTGCTTGTTT-5

SP13'UtR 5'GGGAATGATAGCCCA-CTIGATTA-3' (MUT)
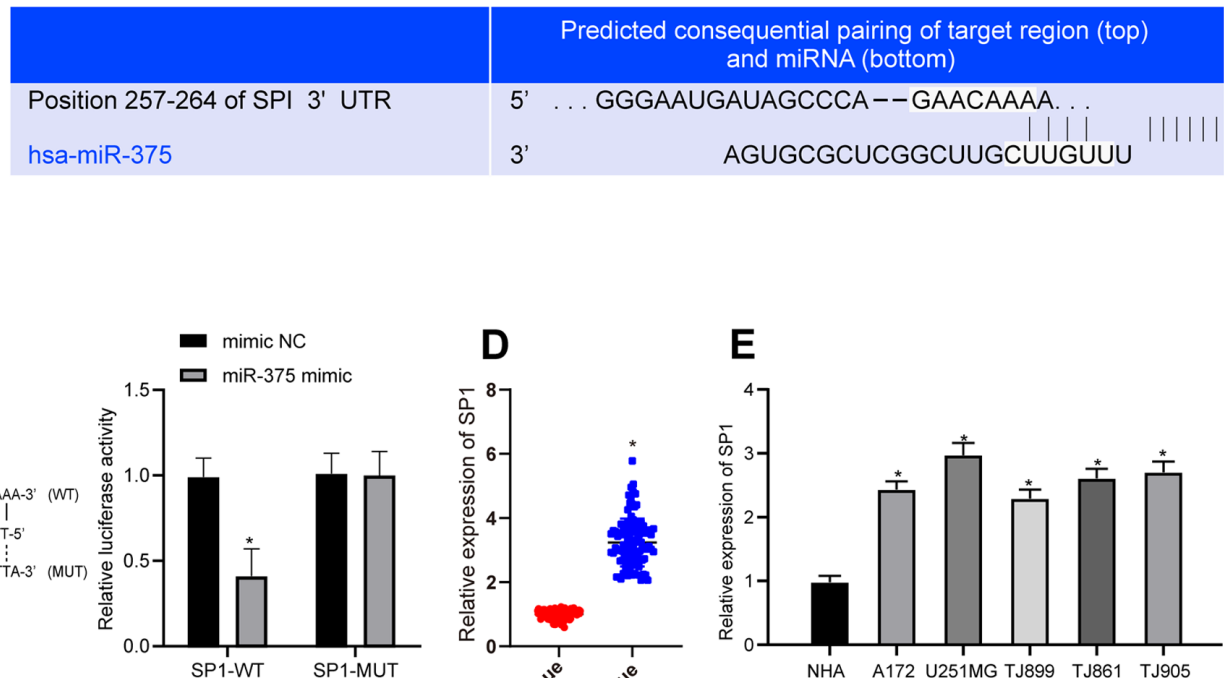

D

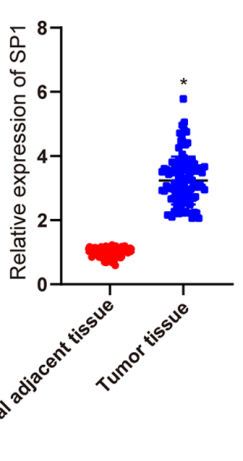

E

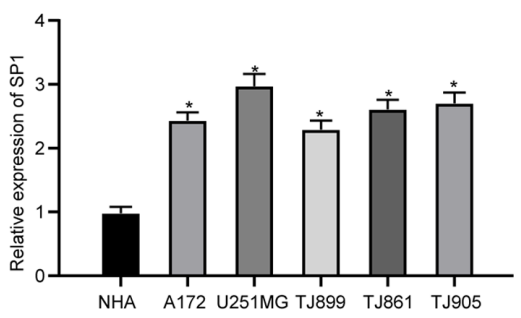

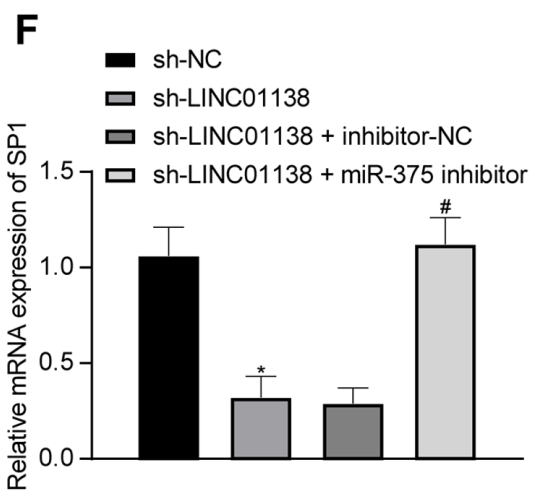
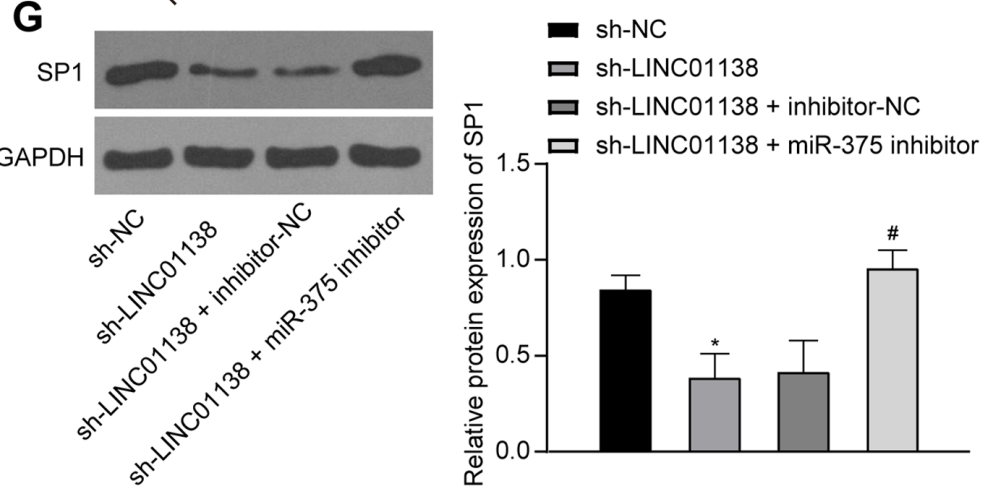

Figure 6. LINC01138 can promote SP1 expression by competing with SP1 for binding to miR-375. (A) SP1 expression data in human glioma tissues from The Cancer Genome Atlas database, red represents tumor and grey normal tissue and SP1is highly expressed in tumor tissue. (B) miR-375 and SP1 binding site was predicted using TargetScan software. (C) miR-375 and SP1 binding relationship was confirmed by the dual-luciferase reporter assay. * $<0.05$ vs. mimic-NC. (D) SP1 mRNA expression levels in human glioma tissues and adjacent normal brain tissues was determined by RT-qPCR, n=108. * $<0.05$ vs. adjacent normal tissues. (E) SP1 mRNA expression levels in NHAs and human brain glioma cell lines were verified by RT-qPCR. *P<0.05 vs. NHAs. (F) SP1 mRNA expression levels in differently transfected cells were measured by RT-qPCR. (G) SP1 protein expression levels in cells were determined by western blotting. ${ }^{*} \mathrm{P}<0.05$ vs. sh-NC. ${ }^{\#} \mathrm{P}<0.05$ vs. sh-LINC01138 + inhibitor-NC group. Three independent repeated cell experiments were conducted. Data are presented as the mean \pm SD. Data were analyzed using (C) two-way ANOVA and Tukey's multiple comparisons test; (D) independent samples t-test; and (E-G) one-way ANOVA and Tukey's multiple comparisons test. miR, microRNA; LINC, long intergenic non-protein coding RNA; SP1, specificity protein 1; NC, negative control; RT-qPCR, reverse transcription-quantitative PCR; NHA, normal human astrocytes; sh, short hairpin RNA; WT, wild-type; MUT, mutant; num(T), number of tumor samples; num(N), number of normal adjacent tissue samples; GBM, glioblastoma.

\section{Discussion}

Glioma is one of the most prevalent and malignant endocranial neoplasms, characterized by rapid infiltration and cell growth, cellular heterogeneity, chemical resistance and a high incidence of relapse (48). Numerous lncRNAs are involved in the development and progression of glioma, mediating cancer cell growth, apoptosis, invasiveness and colony formation (49). LINC01138 has been reported to function as a biological marker of prostate cancer, promoting tumor proliferation and reducing cancer cell apoptosis (50), indicating the deleterious effect of LINC01138 in tumor progression. The present study was therefore designed to identify potential new therapeutic targets for glioma based on LINC01138. The results demonstrated that silencing LINC01138 attenuated aerobic glycolysis and the proliferation of glioma cells via the LINC01138/miR-375/SP1 ceRNA network. To the best of our knowledge, this is the first study to report the specific mechanism by which LINC01138 functions in glioma.

The present study demonstrated that LINC01138 was significantly more strongly expressed in glioma cells compared with in NHAs, and it was associated with the following clinicopathological features of the tumor: WHO tumor grade, lymph node metastasis and tumor diameter. High WHO tumor grade indicates progressive and aggressive glioma with dangerous and unpredictable consequences (51). Tumor diameter and lymph node metastasis are both valuable prognostic indicators for patients with glioma (52). Recent studies have reported that 
A

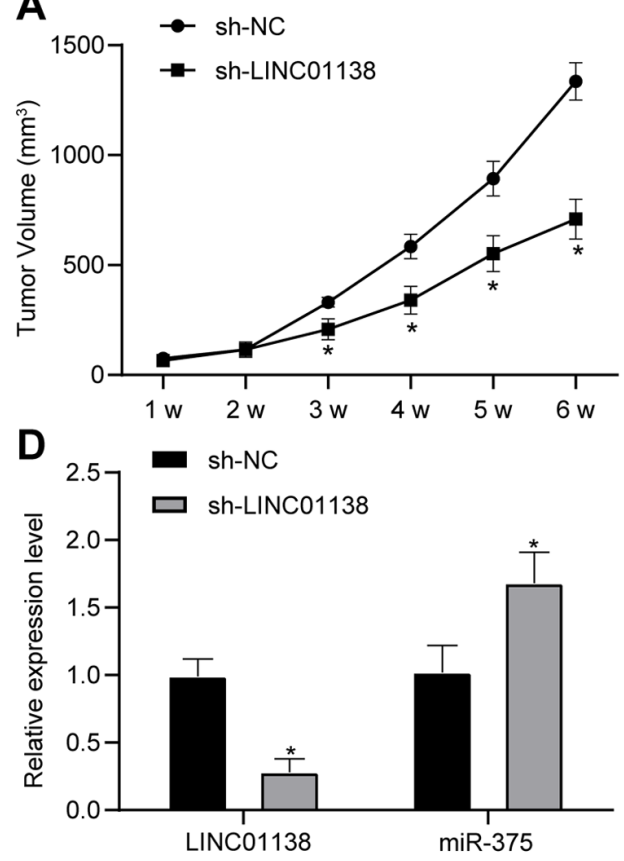

B

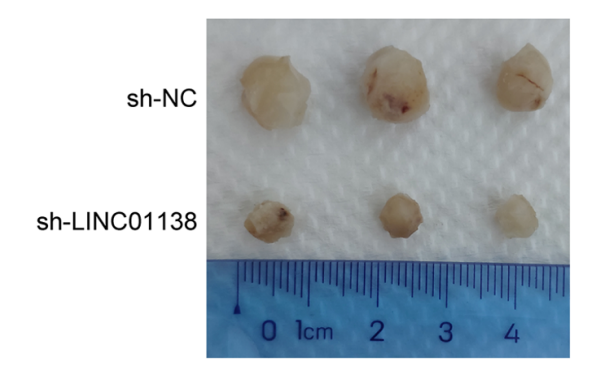

E

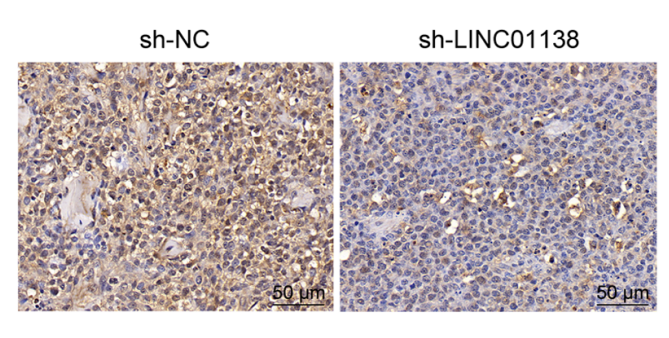

C
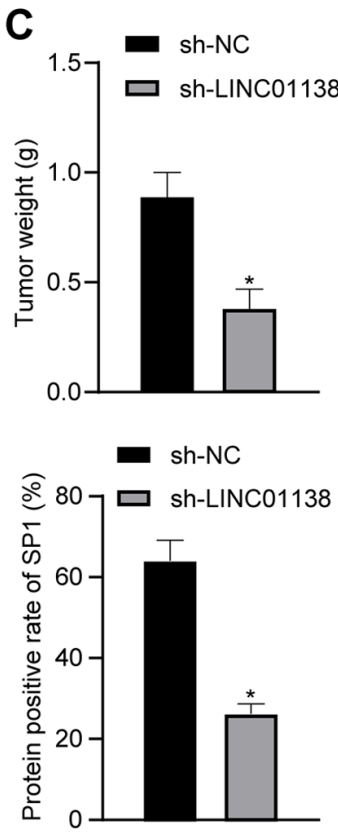

Figure 7. Silencing LINC01138 inhibits tumor growth in vivo. (A) Tumor growth curve in nude mice following LINC01138 silencing. (B) Representative images of glioma tumors in nude mice following LINC01138 silencing. (C) Weight of glioma tumors in nude mice following LINC01138 silencing. (D) LINC01138 and miR-375 expression levels in glioma tissues were determined by reverse transcription-quantitative PCR. (E) Specificity protein 1 protein expression levels in glioma tissues were determined by immunohistochemical staining. " $\mathrm{P}<0.05$ vs. sh-NC; n=8. Data were analyzed using (A) two-way ANOVA and Tukey's multiple comparisons test; and (C and E) independent samples t-test; and (D) one-way ANOVA and Tukey's multiple comparisons test. LINC, long intergenic non-protein coding RNA; miR, microRNA; NC, negative control; sh, short hairpin RNA.

LINC01138 overexpression resulted in a poor overall survival rate and progression-free survival rate in patients with hepatocellular carcinoma (HCC) $(53,54)$. LINC01138 was also revealed to be highly expressed in patients with gastric cancer displaying increased tumor cell biological activities, including invasiveness, viability, apoptosis evasion and expansion (21). To the best of our knowledge, there are currently no reports on LINC01138 expression and function in normal astrocytes and other normal cells. Based on this aforementioned evidence, it was hypothesized that LINC01138 was detrimental to glioma reduction.

Aerobic glycolysis is a notable characteristic of malignant tumor growth and poor clinical outcomes (12). High-grade glioma heavily depends on aerobic glycolysis to promote cancer growth and metabolic activities (55). Subsequently, in the present study LINC01138 expression was silenced in U251MG and TJ905 cells using sh-LINC01138. Silencing LINC01138 significantly inhibited aerobic glycolysis and the proliferation of human glioma cells, indicated by the significantly reduced levels of glucose uptake and lactic acid secretion, as well as significantly decreased protein expression levels of HK, PK, PFK and GLUT. The biological process of aerobic glycolysis in glioma has been shown to reduce the efficacy of medical treatments (48). Du et al (56) reported that glucose uptake and lactic acid secretion, as a result of aerobic glycolysis, greatly exacerbated glioma progression. Furthermore, another study demonstrated that when HK and PK levels were exhausted, glucose levels decreased in glioma cells and effective treatment could be facilitated (37). Moreover, PFK activation in glioma has been shown to accelerate cell growth, and aerobic glycolysis (57). GLUT deficiency has also been reported to limit glioma development and potentiate chemotherapy efficiency (58). The present study reported that knockdown of LINC01138 decreased the levels of these aforementioned proteins, and therefore silencing LINC01138 may be conducive to ameliorating glioma progression.

Previous studies suggested that the interaction between LINC01138 and protein arginine methyltransferase 5 was involved in malignant carcinomas, such as ccRCC and HCC $(19,54)$, indicating the possibility of LINC01138 acting as a ceRNA. The present study demonstrated that LINC01138 acted as a ceRNA to sponge miR-375, and that miR-375 expression was significantly decreased in glioma cells compared with in NHAs. It was recently documented that miR-375 was expressed at low levels in glioma, and inhibited tumor growth and cancer cell proliferation (59). miR-375 has been reported to function in regulating glioma cell proliferation, with the addition of the miR-375 inhibitor enhancing cell proliferation in both U251MG and U87-MG cells (60). miR-375 is a multi-functional regulator in a diverse range of cellular pathways, which can regulate numerous functional genes (61). Ectopic expression of miR-375 is usually associated with pathological changes and the functions of miR-375 in immunity, such as its relevance with macrophages, $T$ helper cells and autoimmune diseases. For instance, miR-375 can reduce apoptosis of macrophages in mice with liver failure; miR-375 is involved in Th1 and Th2 inflammatory and immune responses; IL-10-deficient mice are the animal models of Th1-mediated inflammatory bowel disease and miR-375 is notably elevated in the mice (61). For example, miR-375 expression has been reported to be downregulated in rheumatoid arthritis blood samples and fibroblast-like synoviocytes (62). To date, to the 
best of our knowledge, there are no studies investigating the interaction between miR-375 and astrocytes.

In the present study, functional rescue experiments were performed using a miR-375 inhibitor to verify the role of miR-375 in glioma. miR-375 inhibition reversed the effect of sh-LINC01138 on aerobic glycolysis and cell proliferation in human glioma. A recent study also demonstrated that miR-375-3p inhibited glucose uptake and lactic acid secretion to suppress laryngeal squamous cell carcinoma (63). The present study revealed that LINC01138 promoted SP1 expression by competing with SP1 for binding to miR-375. SP1 expression is often related to poor prognosis and increased resistance of glioma to treatments $(31,34)$. The relationship between miR-375 and SP1 has been detailed in numerous studies. miR-375 targeted SP1 to attenuate inflammatory reactions and oxidative stress, relieving the neuronal injury caused by Parkinson's disease (64). In addition, SP1 depletion was shown to decrease glucose uptake, and inhibit cell proliferation and invasion of U251MG cells by downregulating GLUT3 expression (65). Moreover, Zhang et al (66) revealed that IncRNA RP11-626G11.3 increased SP1 expression by sponging miR-375 to exacerbate malignant glioma. In summary, the ceRNA effect of the LINC01138/miR-375/SP1 axis was verified in glioma.

In conclusion, the present study suggested that silencing LINC01138 ameliorated glioma progression by sponging miR-375 and downregulating SP1 expression. These results have therapeutic implications for glioma treatment. Future work will further explore the underlying mechanisms of the LINC01138/miR-375/SP1 axis in glioma and the corresponding potential therapeutic targets. In the in vivo experiments, the effect of LINC01138 on tumor growth was observed; however, glycolysis-related indicators were not investigated in these tumor tissues. Therefore, the mechanism of aerobic glycolysis in glioma in in vivo models will be investigated further in future work. Although the findings of the present study have implications for glioma treatment, the experimental results and their effective application in clinical practice require further validation.

\section{Acknowledgements}

Not applicable.

\section{Funding}

No funding was received.

\section{Availability of data and materials}

The datasets used and/or analyzed during the current study are available from the corresponding author on reasonable request.

\section{Authors' contributions}

CX and CS conceptualized the present study. HY and XJ carried out the research, data review and writing. CS drafted the study and revised it critically for important intellectual content. CX and CS confirm the authenticity of all the raw data. All authors read and approved the final manuscript.

\section{Ethics approval and consent to participate}

The present study was approved and supervised by the ethics committee of The First Affiliated Hospital of Soochow University (Suzhou, China; approval no. SDU-MED-2017-085), and was in accordance with the Declaration of Helsinki. All patients signed written informed consent forms. Animal experiments were approved by the Animal Ethics Committee of The First Affiliated Hospital of Soochow University (approval no. S20200616018).

\section{Patient consent for publication}

Not applicable.

\section{Competing interests}

The authors declare that they have no competing interests.

\section{References}

1. Matteoni S, Abbruzzese C, Villani V, Malorni W, Pace A, Matarrese P and Paggi MG: The influence of patient sex on clinical approaches to malignant glioma. Cancer Lett 468: 41-47, 2020.

2. Kunadis E, Lakiotaki E, Korkolopoulou P and Piperi C: Targeting post-translational histone modifying enzymes in glioblastoma. Pharmacol Ther 220: 107721, 2021.

3. Angelopoulou E, Paudel YN and Piperi C: Critical role of HOX transcript antisense intergenic RNA (HOTAIR) in gliomas. J Mol Med (Berl) 98: 1525-1546, 2020.

4. Ostrom QT, Bauchet L, Davis FG, Deltour I, Fisher JL, Langer CE, Pekmezci M, Schwartzbaum JA, Turner MC, Walsh KM, et al: The epidemiology of glioma in adults: A 'state of the science' review. Neuro Oncol 16: 896-913, 2014.

5. Molinaro AM, Taylor JW, Wiencke JK and Wrensch MR: Genetic and molecular epidemiology of adult diffuse glioma. Nat Rev Neurol 15: 405-417, 2019.

6. Zhou X, Zhang S, Niu X, Li T, Zuo M, Yang W, Li M, Li J, Yang Y, Wang X, et al: Risk factors for early mortality among patients with glioma: A population-based study. World Neurosurg 136: e496-e503, 2020.

7. Radin DP and Tsirka SE: Interactions between tumor cells, neurons, and microglia in the glioma microenvironment. Int J Mol Sci 21: 8476, 2020.

8. Hakar MH and Wood MD: Updates in pediatric glioma pathology. Surg Pathol Clin 13: 801-816, 2020.

9. McCrorie P, Vasey CE, Smith SJ, Marlow M, Alexander C and Rahman R: Biomedical engineering approaches to enhance therapeutic delivery for malignant glioma. J Control Release 328: 917-931, 2020.

10. Wank M, Schilling D, Schmid TE, Schmid TE, Meyer B, Gempt J, Barz M, Schlegel J, Liesche F, Kessel KA, et al: Human glioma migration and infiltration properties as a target for personalized radiation medicine. Cancers (Basel) 10: 456, 2018.

11. Tech K, Deshmukh M and Gershon TR: Adaptations of energy metabolism during cerebellar neurogenesis are co-opted in medulloblastoma. Cancer Lett 356: 268-272, 2015.

12. Kim MS, Huang Y, Lee J, Zhong X, Jiang WW, Ratovitski EA and Sidransky D: Cellular transformation by cigarette smoke extract involves alteration of glycolysis and mitochondrial function in esophageal epithelial cells. Int J Cancer 127: 269-281, 2010.

13. Zoraghi R, See RH, Gong H, Lian T, Swayze R, Finlay BB, Brunham RC, McMaster WR and Reiner NE: Functional analysis, overexpression, and kinetic characterization of pyruvate kinase from methicillin-resistant Staphylococcus aureus. Biochemistry 49: 7733-7747, 2010.

14. Snášel J, Machová I, Šolínová V, Kašička V, Krečmerová M and Pichová I: Phosphofructokinases A and B from mycobacterium tuberculosis display different catalytic properties and allosteric regulation. Int J Mol Sci 22: 22, 2021.

15. Sánchez-Alvarez R, Tabernero A and Medina JM: Endothelin-1 stimulates the translocation and upregulation of both glucose transporter and hexokinase in astrocytes: Relationship with gap junctional communication. J Neurochem 89: 703-714, 2004. 
16. Stieber D, Abdul Rahim SA and Niclou SP: Novel ways to target brain tumour metabolism. Expert Opin Ther Targets 15: $1227-1239,2011$

17. Bhan A, Soleimani M and Mandal SS: Long noncoding RNA and cancer: A new paradigm. Cancer Res 77: 3965-3981, 2017.

18. Xue BZ, Xiang W, Zhang Q, Wang YH, Wang HF, Yi DY, Xiong NX, Jiang XB, Zhao HY and Fu P: Roles of long non-coding RNAs in the hallmarks of glioma. Oncol Lett 20: 83, 2020 .

19. Zhang X, Wu J, Wu C, Chen W, Lin R, Zhou Y and Huang X: The LINC01138 interacts with PRMT5 to promote SREBP1-mediated lipid desaturation and cell growth in clear cell renal cell carcinoma. Biochem Biophys Res Commun 507: 337-342, 2018.

20. Salmena L, Poliseno L, Tay Y, Kats L and Pandolfi PP: A ceRNA hypothesis: The Rosetta Stone of a hidden RNA language? Cell 146: 353-358, 2011

21. Dou GX, Zhang JN, Wang P, Wang JL and Sun GB: Long intergenic non-protein-coding RNA 01138 accelerates tumor growth and invasion in gastric cancer by regulating miR-1273e. Med Sci Monit 25: 2141-2150, 2019.

22. Zhou Q, Liu J, Quan J, Liu W, Tan H and Li W: MicroRNAs as potential biomarkers for the diagnosis of glioma: A systematic review and meta-analysis. Cancer Sci 109: 2651-2659, 2018.

23. Hu C, Lv L, Peng J, Liu D, Wang X, Zhou Y and Huo J: MicroRNA-375 suppresses esophageal cancer cell growth and invasion by repressing metadherin expression. Oncol Lett 13: 4769-4775, 2017

24. Zhao L, Lou G, Li A and Liu Y: IncRNA MALAT1 modulates cancer stem cell properties of liver cancer cells by regulating YAP1 expression via miR 375 sponging. Mol Med Rep 22: $1449-1457,2020$.

25. Xu F, Ye ML, Zhang YP, Li WJ, Li MT, Wang HZ, Qiu X, Xu Y, Yin JW, Hu Q, et al: MicroRNA-375-3p enhances chemosensitivity to 5-fluorouracil by targeting thymidylate synthase in colorectal cancer. Cancer Sci 111: 1528-1541, 2020.

26. Tang H, Huang X, Wang J, Yang L, Kong Y, Gao G, Zhang L, Chen ZS and Xie X: circKIF4A acts as a prognostic factor and mediator to regulate the progression of triple-negative breast cancer. Mol Cancer 18: 23, 2019.

27. Liu J, Zhan Y, Wang J, Wang J, Guo J and Kong D: IncRNASNHG17 promotes colon adenocarcinoma progression and serves as a sponge for miR-375 to regulate CBX3 expression. Am J Transl Res 12: 5283-5295, 2020.

28. Wang X, Han L, Zhou L, Wang L and Zhang LM: Prediction of candidate RNA signatures for recurrent ovarian cancer prognosis by the construction of an integrated competing endogenous RNA network. Oncol Rep 40: 2659-2673, 2018.

29. Lu M, Xu X, Xi B, Dai Q, Li C, Su L, Zhou X, Tang M, Yao Y and Yang J: Molecular network-based identification of competing endogenous RNAs in thyroid carcinoma. Genes (Basel) 9: 44, 2018.

30. Liang Y, Zhang C, Ma MH and Dai DQ: Identification and prediction of novel non-coding and coding RNA-associated competing endogenous RNA networks in colorectal cancer. World J Gastroenterol 24: 5259-5270, 2018.

31. Yang WB, Hsu CC, Hsu TI, Liou JP, Chang KY, Chen PY, Liu JJ, Yang ST, Wang JY, Yeh SH, et al: Increased activation of HDAC1/2/6 and Spl underlies therapeutic resistance and tumor growth in glioblastoma. Neuro Oncol 22: 1439-1451, 2020.

32. Zhang X, Zhao X, Wang Y and Xing L: Long non-coding RNA LINC00491 contributes to the malignancy of non-small-cell lung cancer via competitively binding to microRNA-324-5p and thereby increasing specificity protein 1 expression. Cancer Manag Res 12: 6779-6793, 2020.

33. Cong Z, Diao Y, Xu Y, Li X, Jiang Z, Shao C, Ji S, Shen Y, De W and Qiang Y: Long non-coding RNA linc00665 promotes lung adenocarcinoma progression and functions as ceRNA to regulate AKR1B10-ERK signaling by sponging miR-98. Cell Death Dis 10: 84, 2019.

34. Guan H, Cai J, Zhang N, Wu J, Yuan J, Li J and Li M: Sp1 is upregulated in human glioma, promotes MMP-2-mediated cell invasion and predicts poor clinical outcome. Int J Cancer 130 : 593-601, 2012

35. Percie du Sert N, Hurst V, Ahluwalia A, Alam S, Avey MT, Baker M, Browne WJ, Clark A, Cuthill IC, Dirnagl U, et al: The ARRIVE guidelines 2.0: Updated guidelines for reporting animal research. PLoS Biol 18: e3000410, 2020

36. Villa C, Miquel C, Mosses D, Bernier M and Di Stefano AL: The 2016 World Health Organization classification of tumours of the central nervous system. Presse Med 47: e187-e200, 2018.
37. Xu B, Zhang Q, Luo X, Ning X, Luo J, Guo J, Liu Q, Ling G and Zhou N: Selenium nanoparticles reduce glucose metabolism and promote apoptosis of glioma cells through reactive oxygen species-dependent manner. Neuroreport 31: 226-234, 2020.

38. Tang Z, Li C, Kang B, Gao G, Li C and Zhang Z: GEPIA: A web server for cancer and normal gene expression profiling and interactive analyses. Nucleic Acids Res 45: W98-W102, 2017.

39. Cao Z, Pan X, Yang Y, Huang Y and Shen HB: The lncLocator: A subcellular localization predictor for long non-coding RNAs based on a stacked ensemble classifier. Bioinformatics 34: 2185-2194, 2018.

40. Miranda KC, Huynh T, Tay Y, Ang YS, Tam WL, Thomson AM, Lim B and Rigoutsos I: A pattern-based method for the identification of MicroRNA binding sites and their corresponding heteroduplexes. Cell 126: 1203-1217, 2006.

41. Agarwal V, Bell GW, Nam JW and Bartel DP: Predicting effective microRNA target sites in mammalian mRNAs. eLife 4: 4, 2015.

42. Zhang E, Han L, Yin D, He X, Hong L, Si X, Qiu M, Xu T, De W, $\mathrm{Xu} \mathrm{L}$, et al: H3K27 acetylation activated-long non-coding RNA CCAT1 affects cell proliferation and migration by regulating SPRY4 and HOXB13 expression in esophageal squamous cell carcinoma. Nucleic Acids Res 45: 3086-3101, 2017.

43. Livak KJ and Schmittgen TD: Analysis of relative gene expression data using real-time quantitative PCR and the 2(- $\Delta \Delta \mathrm{C}(\mathrm{T}))$ method. Methods 25: 402-408, 2001.

44. Diehl KH, Hull R, Morton D, Pfister R, Rabemampianina Y, Smith D, Vidal JM and van de Vorstenbosch C; European Federation of Pharmaceutical Industries Association and European Centre for the Validation of Alternative Methods: A good practice guide to the administration of substances and removal of blood, including routes and volumes. J Appl Toxicol 21: 15-23, 2001.

45. Cheng R, Chen Y, Zhou H, Wang B, Du Q and Chen Y: B7-H3 expression and its correlation with clinicopathologic features, angiogenesis, and prognosis in intrahepatic cholangiocarcinoma. APMIS 126: 396-402, 2018.

46. Cerdán S, Rodrigues TB, Sierra A, Benito M, Fonseca LL, Fonseca CP and García-Martín ML: The redox switch/redox coupling hypothesis. Neurochem Int 48: 523-530, 2006.

47. Jiang B: Aerobic glycolysis and high level of lactate in cancer metabolism and microenvironment. Genes Dis 4: 25-27, 2017.

48. Han W, Shi J, Cao J, Dong B and Guan W: Emerging roles and therapeutic interventions of aerobic glycolysis in glioma. OncoTargets Ther 13: 6937-6955, 2020.

49. Han W, Shi J, Cao J, Dong B and Guan W: Current advances of long non-coding RNAs mediated by wnt signaling in glioma. Pathol Res Pract 216: 153008, 2020.

50. Wan X, Huang W, Yang S, Zhang Y, Pu H, Fu F, Huang Y, Wu H, $\mathrm{Li} \mathrm{T}$ and $\mathrm{Li} \mathrm{Y}$ : Identification of androgen-responsive lncRNAs as diagnostic and prognostic markers for prostate cancer. Oncotarget 7: 60503-60518, 2016.

51. van Kessel E, Huenges Wajer IM, Ruis C, Seute T, Fonville S, De Vos FY, Verhoeff JJ, Robe PA, van Zandvoort MJ and Snijders TJ: Cognitive impairments are independently associated with shorter survival in diffuse glioma patients. J Neurol 268: 1434-1442, 2021

52. Li K, Zhang Q, Niu D and Xing H: Mining miRNAs' expressions in glioma based on GEO database and their effects on biological functions. BioMed Res Int 2020: 5637864, 2020.

53. Jiang H, Shi X, Ye G, Xu Y, Xu J, Lu J and Lu W: Up-regulated long non-coding RNA DUXAP8 promotes cell growth through repressing Krüppel-like factor 2 expression in human hepatocellular carcinoma. OncoTargets Ther 12: 7429-7436, 2019.

54. Li Z, Zhang J, Liu X, Li S, Wang Q, Di Chen, Hu Z, Yu T, Ding J, Li J, et al: The LINC01138 drives malignancies via activating arginine methyltransferase 5 in hepatocellular carcinoma. Nat Commun 9: 1572, 2018

55. Sperry J, Condro MC, Guo L, Braas D, Vanderveer-Harris N, Kim KK, Pope WB, Divakaruni AS, Lai A, Christofk H, et al: Glioblastoma utilizes fatty acids and ketone bodies for growth allowing progression during Ketogenic Diet Therapy. iScience 23: 101453, 2020.

56. Du P, Liao Y, Zhao H, Zhang J, Muyiti, Keremu and Mu K: ANXA2P2/miR-9/LDHA axis regulates Warburg effect and affects glioblastoma proliferation and apoptosis. Cell Signal 74: 109718, 2020.

57. Lee JH, Liu R, Li J, Zhang C, Wang Y, Cai Q, Qian X, Xia Y, Zheng Y, Piao Y, et al: Stabilization of phosphofructokinase 1 platelet isoform by AKT promotes tumorigenesis. Nat Commun 8: 949, 2017 
58. Azzalin A, Brambilla F, Arbustini E, Basello K, Speciani A, Mauri P, Bezzi P and Magrassi L: A new pathway promotes adaptation of human glioblastoma cells to glucose starvation. Cells 9: 1249, 2020.

59. Li GF, Cheng YY, Li BJ, Zhang C, Zhang XX, Su J, Wang C, Chang L, Zhang DZ, Tan CL, et al: miR-375 inhibits the proliferation and invasion of glioblastoma by regulating Wnt5a. Neoplasma 66: 350-356, 2019.

60. Ding P, Liang B, Shou J and Wang X: lncRNA KCNQ1OT1 promotes proliferation and invasion of glioma cells by targeting the miR 375/YAP pathway. Int J Mol Med 46: 1983-1992, 2020.

61. Liu Y, Wang Q, Wen J, Wu Y and Man C: MiR-375: A novel multifunctional regulator. Life Sci 275: 119323, 2021.

62. Zhi L, Liang J, Huang W, Ma J, Qing Z and Wang X: Circ_ AFF2 facilitates proliferation and inflammatory response of fibroblast-like synoviocytes in rheumatoid arthritis via the miR-375/TAB2 axis. Exp Mol Pathol 119: 104617, 2021.

63. Chang K, Wei Z and Cao H: miR-375-3p inhibits the progression of laryngeal squamous cell carcinoma by targeting hepatocyte nuclear factor-1 $\beta$. Oncol Lett 20: 80, 2020.
64. Cai LJ, Tu L, Li T, Yang XL, Ren YP, Gu R, Zhang Q, Yao H, Qu X, Wang Q, et al: Up-regulation of microRNA-375 ameliorates the damage of dopaminergic neurons, reduces oxidative stress and inflammation in Parkinson's disease by inhibiting SP1. Aging (Albany NY) 12: 672-689, 2020.

65. Zheng C, Yang K, Zhang M, Zou M, Bai E, Ma Q and Xu R: Specific protein 1 depletion attenuates glucose uptake and proliferation of human glioma cells by regulating GLUT3 expression. Oncol Lett 12: 125-131, 2016.

66. Zhang Y, Mou C, Shang M, Jiang M and Xu C: Long noncoding RNA RP11-626G11.3 promotes the progression of glioma through miR-375-SP1 axis. Mol Carcinog 59: 492-502, 2020.

This work is licensed under a Creative Commons Attribution-NonCommercial-NoDerivatives 4.0 International (CC BY-NC-ND 4.0) License. 